\title{
SUMMARY OF GROUT DEVELOPMENT AND TESTING FOR SINGLE SHELL TANK CLOSURE AT HANFORD
}

John R. Harbour

April 28, 2005

Immobilization Technology Section Savannah River National Laboratory Aiken, SC 29808 


\title{
DISCLAIMER
}

This report was prepared by Westinghouse Savannah River Company (WSRC) for the United States Department of Energy under Contract No. DE-AC09-96SR18500 and is an account of work performed under that contract. Neither the United States Department of Energy, nor WSRC, nor any of their employees makes any warranty, expressed or implied, or assumes any legal liability or responsibility for the accuracy, completeness, or usefulness, of any information, apparatus, or product or process disclosed herein or represents that its use will not infringe privately owned rights. Reference herein to any specific commercial product, process, or service by trademark, name, manufacturer or otherwise does not necessarily constitute or imply endorsement, recommendation, or favoring of same by WSRC or by the United States Government or any agency thereof. The views and opinions of the authors expressed herein do not necessarily state or reflect those of the United States Government or any agency thereof.

\author{
Printed in the United States of America \\ Prepared For \\ U.S. Department of Energy
}


Key Words: Blast Furnace Slag Technetium

Portland Cement

Retention: Permanent

\section{SUMMARY OF GROUT DEVELOPMENT AND TESTING FOR SINGLE SHELL TANK CLOSURE AT HANFORD}

John R. Harbour

April 2005

Immobilization Technology Section Savannah River National Laboratory Aiken, SC 29808

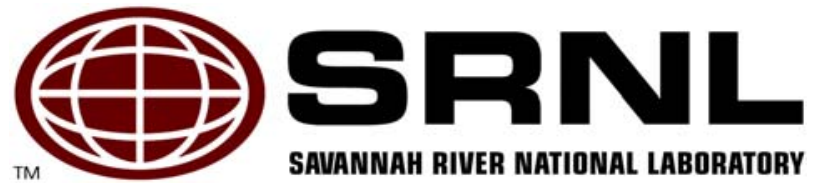


WSRC-TR-2005-00195

Revision 0

\section{REVIEWS AND APPROVALS}

\section{AUTHORS:}

Ghm RHarlour

$5 / 19 / 05$

1. R. Harbour, Immobilization Technology Section

\section{TECHNICAL REVIEWERS:}

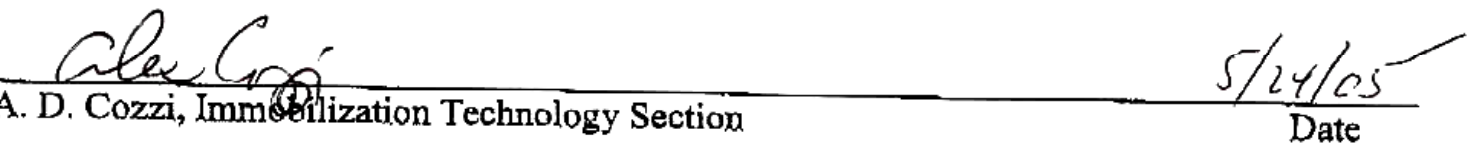

\section{APPROVERS}

\section{Enathetzon}

E. W. Holtzscheiter, Manager, Immobilization Technology Section

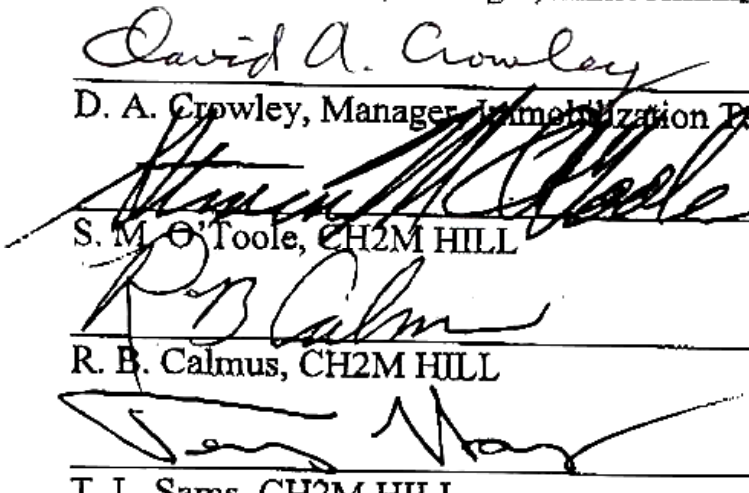

T. L. Sams, CH2M HILL
$5 / 23 \%$ or

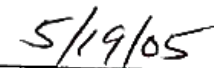




\section{EXECUTIVE SUMMARY}

This report is a summary of the bench-scale and large scale experimental studies performed by Savannah River National Laboratory for CH2M HILL to develop grout design mixes for possible use in producing fill materials as a part of Tank Closure of the Single-Shell Tanks at Hanford. The grout development data provided in this report demonstrates that these design mixes will produce fill materials that are ready for use in Hanford single shell tank closure.

The purpose of this report is to assess the ability of the proposed grout specifications to meet the current requirements for successful single shell tank closure which will include the contracting of services for construction and operation of a grout batch plant. The research and field experience gained by SRNL in the closure of Tanks 17F and 20F at the Savannah River Site was leveraged into the grout development efforts for Hanford. It is concluded that the three Hanford grout design mixes provide fill materials that meet the current requirements for successful placement. This conclusion is based on the completion of recommended testing using Hanford area materials (see Recommendation Section) by the operators of the grout batch plant.

This report summarizes the regulatory drivers and the requirements for grout mixes as tank fill material. It is these requirements for both fresh and cured grout properties that drove the development of the grout formulations for the stabilization, structural and capping layers.

The major tank placement requirements for fresh grout tank are flow (> 12 inches by ASTM C 6103) and a lack of bleed water. Additional properties of concern for placement include the ability to perform a submerged grout placement against a head of fresh grout and the ability to use a Tremie for placement. All of these requirements for fresh properties of grouts were met by the mixes developed for Hanford.

The major requirements for cured properties of grout include compressive strength, set time, and unit weight (density). Additional properties of concern for the cured grout include the effective diffusion coefficient, hydraulic conductivity, shrinkage, temperature rise through the heat of hydration reactions, air content and Young's modulus. Results for these properties are presented and discussed in the report. In particular, it was demonstrated that the capping layer had a compressive strength $>2,000$ psi (to deter an inadvertent intruder), that subsidence prevention will be provided by the structural layer, and that the residual waste (both solid and liquid supernate left at the bottom of the tank after retrieval) will be isolated in the stabilization layer.

A discussion of the durability of the cured grout layers in the single shell tanks is presented in this report. The grout mixes consist mainly of sand (65\% by weight) which is a very stable material that provides longevity to the grouts. The grout layers are isolated in the underground tanks that insulate them from surface conditions thereby protecting the integrity of the layers over time. Examples of ancient structures that used pozzolanic materials in both concrete and mortar (and therefore, can be related to grout mixes) for the construction of buildings, walls (such as Hadrian's Wall), aqueducts and roads are also presented. These structures, some of which were built almost two millennia ago, still stand today in spite of the destructive forces of weather, use, neglect and wars. 
As part of a defense in depth strategy, slag was introduced into the design mixes which in addition to its hydraulic activity, also provides chemical reducing power to the mix.

Technetium-99 under normal oxidizing conditions exists as the mobile pertechnetate anion and is one of the key radionuclides that must be addressed when demonstrating compliance to the groundwater performance objectives. The reducing nature of slag was shown to convert the pertechnetate to an insoluble Tc(IV) species which can significantly reduce the release of Tc-99 to the tank farm fence line.

A proof-of-principle demonstration was performed to show that cascade lines can self-seal during placement of grout in the single shell tank. Self-sealing under normal grout placement will preclude the necessity of sealing these lines by the costly process of excavation and closure. 


\section{TABLE OF CONTENTS}

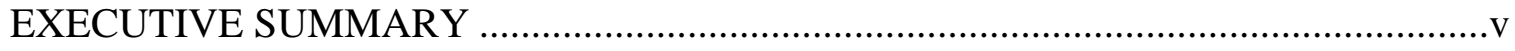

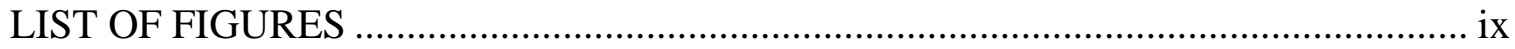

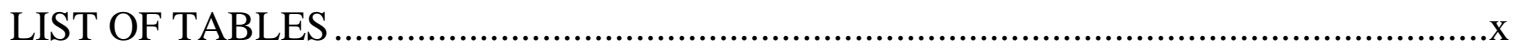

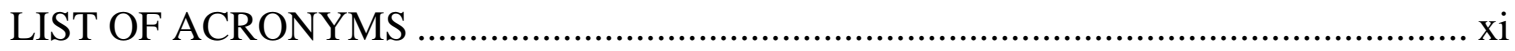

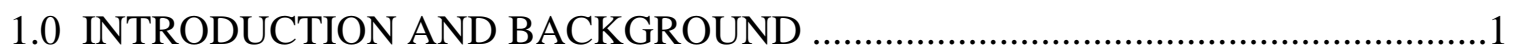

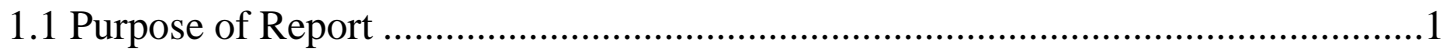

1.2 Definition of Grout ...........................................................................................1

1.3 Description of Hanford Single Shell Tanks .............................................................

2.0 HANFORD CLOSURE REGULATORY DRIVERS .............................................

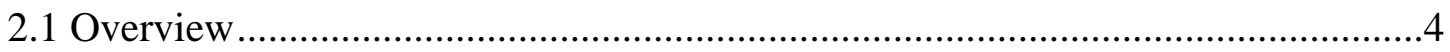

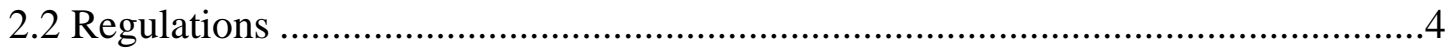

2.3 Core Functions for Tank Fill Driven by Regulations ...............................................

3.0 PHYSICAL NATURE OF THE GROUT IN THE TANK ..........................................

3.1 Placement Properties............................................................................................

3.2 High Flowability and Self-Consolidation ..............................................................

3.3 Segregation and Bleed Water................................................................................

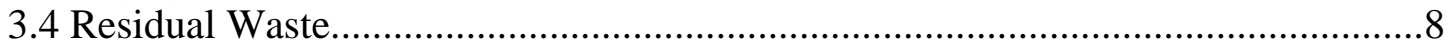

3.5 Placement of the Stabilization Layer ....................................................................

3.6 Placement of the Structural and Capping Layers.....................................................9

3.7 Cured State..........................................................................................................

4.0 REQUIRED GROUT PROPERTIES - FRESH ………….......................................10

4.1 Level 2 Specifications..................................................................................10

4.2 Treatability Variance Requirements .......................................................................10

5.0 REQUIRED GROUT PROPERTIES - CURED ……….........................................11

5.1 Level 2 Specifications.....................................................................................11

5.2 Requirements for Long Term Risk Analyses.........................................................12

5.3 Treatability Variance Requirements ........................................................................13

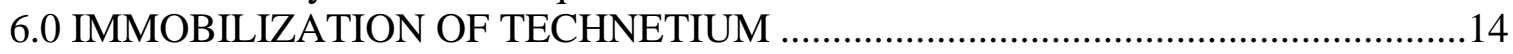

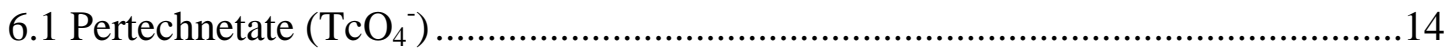

6.2 Reduction and Immobilization...........................................................................

6.3 Re-oxidation of Reduced Technetium .................................................................15

6.4 Tc-99 Sorption and Leaching Tests ...................................................................15

6.4.1 Monolith Leaching Tests (Tc-99) 16

6.4.2 Crushed Monolith Leaching Tests 18

6.4.3 Tc- 99 Sorption and Desorption Tests 19

6.5 Pertechnetate Reduction in Hanford Tank Closure ...............................................19

$\begin{array}{ll}\text { 6.5.1 Tank Supernate } & 19\end{array}$

6.5.2 Residual Tank Solids 20

6.5.3 Oxidation State of Technetium in Residual Solid Waste 20

6.5.4 Leaching Tests on C-203, C-204 and C-106 Residual Waste 20

6.5.5 Grout Encapsulation of Residual Solid Waste 21

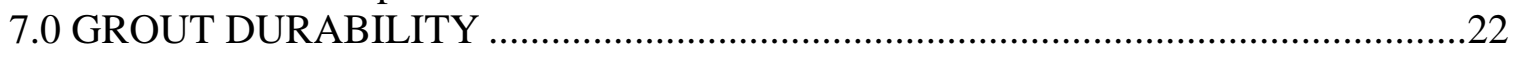

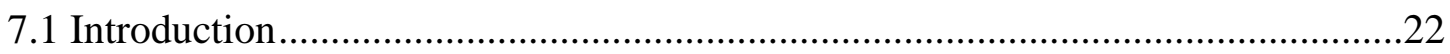

7.2 Monolith Formation ........................................................................................22 


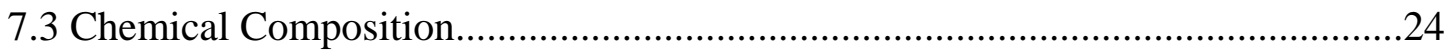

7.4 Potential Degradation Processes ...........................................................................24

7.4.1 Weathering, Abrasion and Mechanical Loads 25

7.4.2 Freeze-Thaw Cycles 25

7.4.3 Alkali-Aggregate Reactions 25

7.4.4 Sulfate attack and delayed ettringite formation 25

7.4.5 Steel Corrosion 26

7.5 Cracking of the Grout Monolith .........................................................................26

$\begin{array}{ll}\text { 7.5.1 Plastic Shrinkage } & 26\end{array}$

$\begin{array}{ll}7.5 .2 \text { Drying } & 27\end{array}$

$\begin{array}{ll}\text { 7.5.3 Thermal Fluctuations } & 27\end{array}$

$\begin{array}{ll}\text { 7.5.4 Structural Stress } & 27\end{array}$

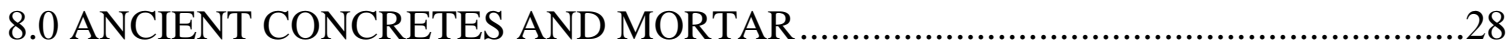

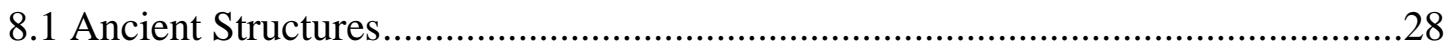

8.1.1 Pantheon 28

8.1.2 Hadrian’s Wall 29

8.1.3 Roman Aqueducts 30

8.2 Chemistry of Ancient Cements and Mortars ……………......................................31

9.0 HANFORD GROUT DESIGN MIXES AND PROPERTIES .....................................32

9.1 Hanford Design Mixes..........................................................................................

9.2 Scale-up Testing and Equivalency .....................................................................32

9.3 Water Content of Sand......................................................................................33

9.4 Operational Flexibility ........................................................................................

9.5 Grout Properties ..................................................................................................

9.5.1 Fresh Grout Properties $\quad 35$

9.5.2 Cured Grout Properties 39

9.6 Equipment Filling with Cable Grouts ..................................................................41

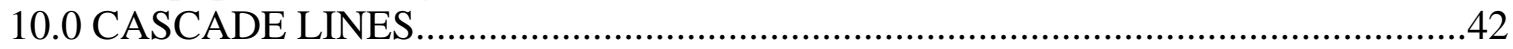

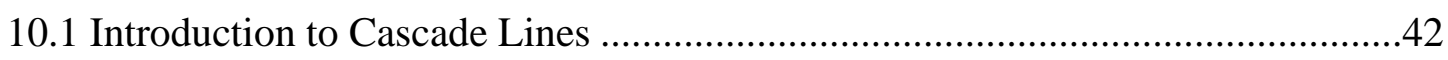

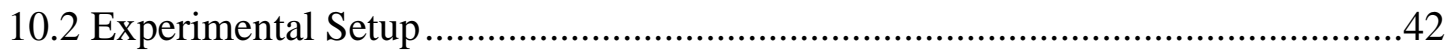

10.3 Results of the Cascade Line Testing......................................................................45

10.4 Discussion of the Cascade Line Testing ...............................................................46

10.5 Conclusions for the Cascade Line Testing.............................................................47

11.0 SAVANNAH RIVER SITE APPROACH TO TANK CLOSURE.............................48

11.1 Waste Removal ............................................................................................48

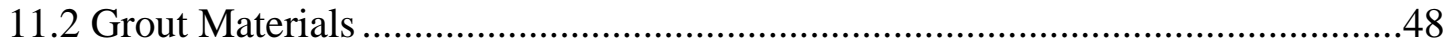

11.2.1 Reducing Grout $\quad 49$

11.2.2 Bulk Fill, Controlled Low Strength Material (CLSM) Layer 50

11.2.3 Strong Grout, Water Layer $\quad 50$

11.2.4 Specifications for Savannah River Mix Designs 50

11.3 Grout Production and Placement ......................................................................51

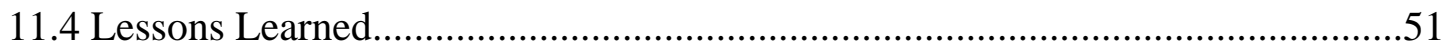

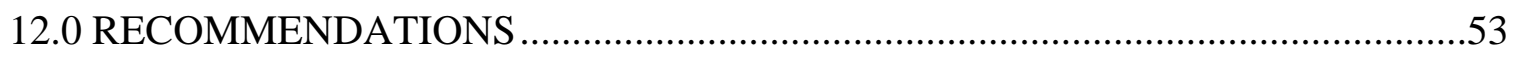

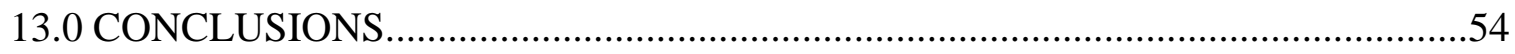

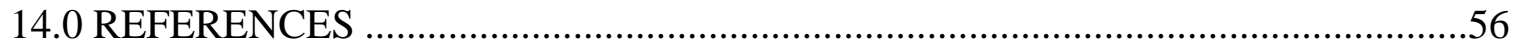




\section{LIST OF FIGURES}

Figure 1-1 Schematic of the C-Farm Series 100 and 200 tanks. 3

Figure 6-1 Photograph of large ( $\sim 0 \mathrm{~mL})$ monoliths prepared for the sorption and desorption testing. For the monolith leaching tests, the monoliths were similar in shape except that they were $30 \mathrm{~mL}$ in volume. 16

Figure 6-2 The first photograph shows monolith leaching with the $30 \mathrm{~mL}$ cylinders in the $500 \mathrm{~mL}$ Teflon vessels. The second photograph shows the vessel immediately after placement of the monolith and prior to capping the vessel.

Figure 6-3 The samples for the crushed monolith leaching tests. Each sample contained 3 grams of crushed sample in $30 \mathrm{~mL}$ of leachate (the blank is on the far left)......

Figure 7-1 Demolition of pool 1 monolith after only 5 days after the capping layer had been poured. The monolith from pool 2 is shown in the foreground. ...... 23

Figure 7-2 Demolition of Pool 2 monolith after only 5 days after the final capping layer was placed. Note that there is also a vertical crack in the structural and capping layer that occurred during this demolition.................... 24

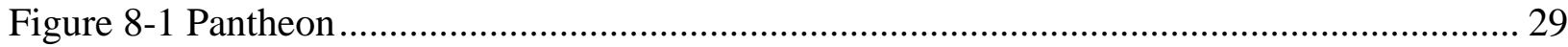

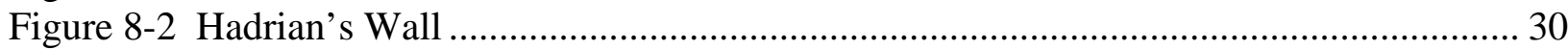

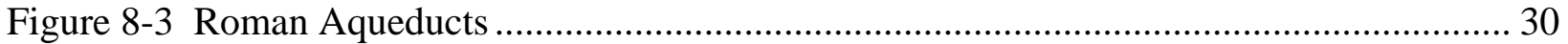

Figure 9-1 The number of gallons of water to be added per cubic yard of grout as a function of the percentage of water in the sand.

Figure 9-2 Photograph taken immediately after placement of the stabilization grout into the $80 \mathrm{ft}$. long trench. ................................................................................ 36

Figure 9-3 Metal culvert looking down from the top. ................................................................. 37

Figure 9-4 Placement of grout into a trench through a Tremie. Note the metal culvert in the foreground which was used for the submerged grout placement test.......................... 38

Figure 9-5 One-inch PVC pipe filled with Masterflow 1205 grout............................................... 41

Figure 10-1 Experimental setup showing the four cascade lines. This photograph was taken during placement of the first truckload of grout into the pool

Figure 10-2 The grout was fed from the Ready Mix truck to the Putzmeister pump hopper and subsequently pumped at a controlled rate to the pool................................ 44

Figure 10-3 The grout flowed approximately 4.5 feet down the cascade line (see the $4 \mathrm{ft}$ mark on top cascade line).

Figure 11-1 Representation of a tank after placement of the three layers of grout at SRS. 


\section{LIST OF TABLES}

Table 2-1 Grout properties of interest versus the core functions................................................... 6

Table 6-1 Binder ingredients and amounts for samples used in the monolith and crushed

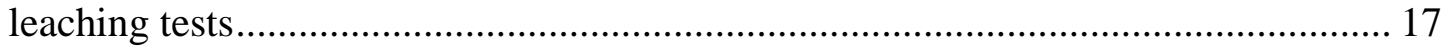

Table 9-1 Design mixes for the stabilization, structural, and capping grouts for Hanford........... 32

Table 9-2 Design mixes for the stabilization, structural, and capping grouts for Hanford Tank Closure using SRS locally available materials. .............................................................. 33

Table 10-1 Approximate values of relevant parameters for the two tests .................................... 45

Table 11-1 Mix designs for the Savannah River Site closure of Tanks 17F and 20F. ................ 51 
WSRC-TR-2005-00195

Revision 0

\section{LIST OF ACRONYMS}

\begin{tabular}{|l|l|}
\hline ANSI & American National Standards Institute \\
\hline ASTM & American Society for Testing and Materials \\
\hline ATCD & Accelerated Tank Closure Demonstration \\
\hline CLSM & Controlled Low Strength Material \\
\hline DIW & Deionized Water \\
\hline DOE & Department of Energy \\
\hline EA & Environmental Assessment \\
\hline EPA & Environmental Protection Agency \\
\hline EXAFS & Extended X-ray Absorption Fine Structure \\
\hline LDR & Land Disposal Requirements \\
\hline HFFACO & Hanford Federal Facility Agreement and Consent Order \\
\hline HRG & Hanford Reducing Grout \\
\hline HWMA & Washington Hazardous Waste Management Act \\
\hline NEPA & National Environmental Policy Act \\
\hline MEPAS & Multimedia Environmental Pollutant Assessment System \\
\hline NRC & Nuclear Regulatory Commission \\
\hline PNNL & Pacific Northwest National Laboratory \\
\hline PVC & Polyvinyl chloride \\
\hline ROD & Record of Decision \\
\hline SNL & Sandia National Laboratory \\
\hline SRG & Savannah River Reducing Grout \\
\hline SRNL & Savannah River National Laboratory \\
\hline SRS & Savannah River Site \\
\hline SST & Single Shell Tanks \\
\hline TCLP & Toxic Characteristic Leaching Procedure \\
\hline XANES & X-ray Absorption Near Edge Spectroscopy \\
\hline WIR & Waste Incidental to Reprocessing \\
\hline
\end{tabular}




\subsection{INTRODUCTION AND BACKGROUND}

\subsection{Purpose of Report}

The purpose of this report is to assess the ability of the proposed grout specifications [1] as developed in this task to meet the requirements for successful single shell tank closure through the contracting of services for construction and operation of a grout batch plant. This report is a summary of experimental studies performed by SRNL for CH2M HILL to develop grout design mixes for possible use in Tank Closure of Single-Shell Tanks (SST) at Hanford [2-5]. The intent of this work was to leverage the research and field experience gained in the closure of Tanks $17 \mathrm{~F}$ and 20F at the Savannah River Site [6,7]. The experimental approach for the Hanford task included both bench-scale and scale-up testing. Presented in this report are the results of this work in light of the performance objectives for Hanford Single Shell Tank Closure. Implementation of the grout option is dependent on the future Record of Decision (ROD) for the Environmental Impact Statement for Retrieval, Treatment, and Disposal of Tank Waste and Closure of Single-Shell Tanks at the Hanford Site Richland, WA [8].

\subsection{Definition of Grout}

Definitions of grout and concrete are somewhat arbitrary, overlapping, and dependent on the application. For example, the term grout is often used for the closure of single shell tanks in the DOE Complex, although the term concrete would have been equally appropriate. For portland cement based mixes, both grouts and concretes use some combination of portland cement, pozzolans, aggregate, admixtures and water to produce a solid. In general concretes use coarse aggregate (gravel, rocks etc.) and produce a mix with relatively low flowability while grouts use finer or no aggregate to increase flowability. Both grout and concrete harden with time through hydraulic activity of the portland cement and pozzolans (if present) such as fly ash and blast furnace slag. The compressive strength of the hardened grout or concrete is controlled by the concentrations of portland cement and pozzolans in the mixes.

Tank closure requires a highly flowable fill. Consequently, a fine aggregate (sand) and a superplasticizer were used in the grout design mixes to close Tanks $17 \mathrm{~F}$ and $20 \mathrm{~F}$ at the Savannah River Site [7]. This fill material was referred to as grout due to the previous use of grout for single shell tank closure and to the highly fluid nature of the mix. Therefore, in this report, the term grout refers to a highly fluid mix containing portland cement, pozzolans such as fly ash and ground granulated blast furnace slag, fine aggregate, admixtures and water. 


\subsection{Description of Hanford Single Shell Tanks}

This task is concerned with closure of the Single-Shell Tanks at Hanford. These underground tanks were constructed in the 200 East and 200 West Areas of the Hanford Site. A total of 149 single-shell tanks were constructed in 12 separate tank farms that were subsequently grouped into 7 waste management areas (WMA). The larger Series 100 tanks have a working capacity of 2,010,000 L to 4,400,000 L (530,000 gallons to 1,150,000 gallons) while the smaller Series 200 tanks have a working capacity of 208,000 L (55,000 gallons) [9,10]. For example, a total of twelve Series 100 tanks (each having a capacity of 2 million L) and four Series 200 tanks were built in C-Farm between December 1943 through February 1945 in the 200 East Area.

The initial schedule for tank closure identified 241 C-106 as the first tank to be closed followed by closure of all four of the 200 series tanks in C-Farm (C-201, C-202, C-203 and C-204).

A schematic of tank $241 \mathrm{C}-106$ is provided in Figure 1-1 [9]. The tank is 75 feet wide and 30 feet tall at the apex of the dome with a dish bottom, is constructed of reinforced concrete and rests on a concrete basemat. A 1/4 inch carbon steel liner is the interior of the tank structure and extends upward to the dome portion of the tank ( $\sim 19 \mathrm{ft}$ from the bottom of the dish to the top of the liner). The apex of the dome is $\sim 7 \mathrm{ft}$. below the surface. A number of risers are present on the surface of the dome with access to these risers through pits.

Figure 1-1 also shows a schematic of the Series 200 tanks found in C-Farm. These tanks have a working volume that is roughly $10 \%$ of the Series 100 tanks, a diameter of $20 \mathrm{ft}$., and a height of $\sim 20 \mathrm{ft}$. 
WSRC-TR-2005-00195

Revision 0
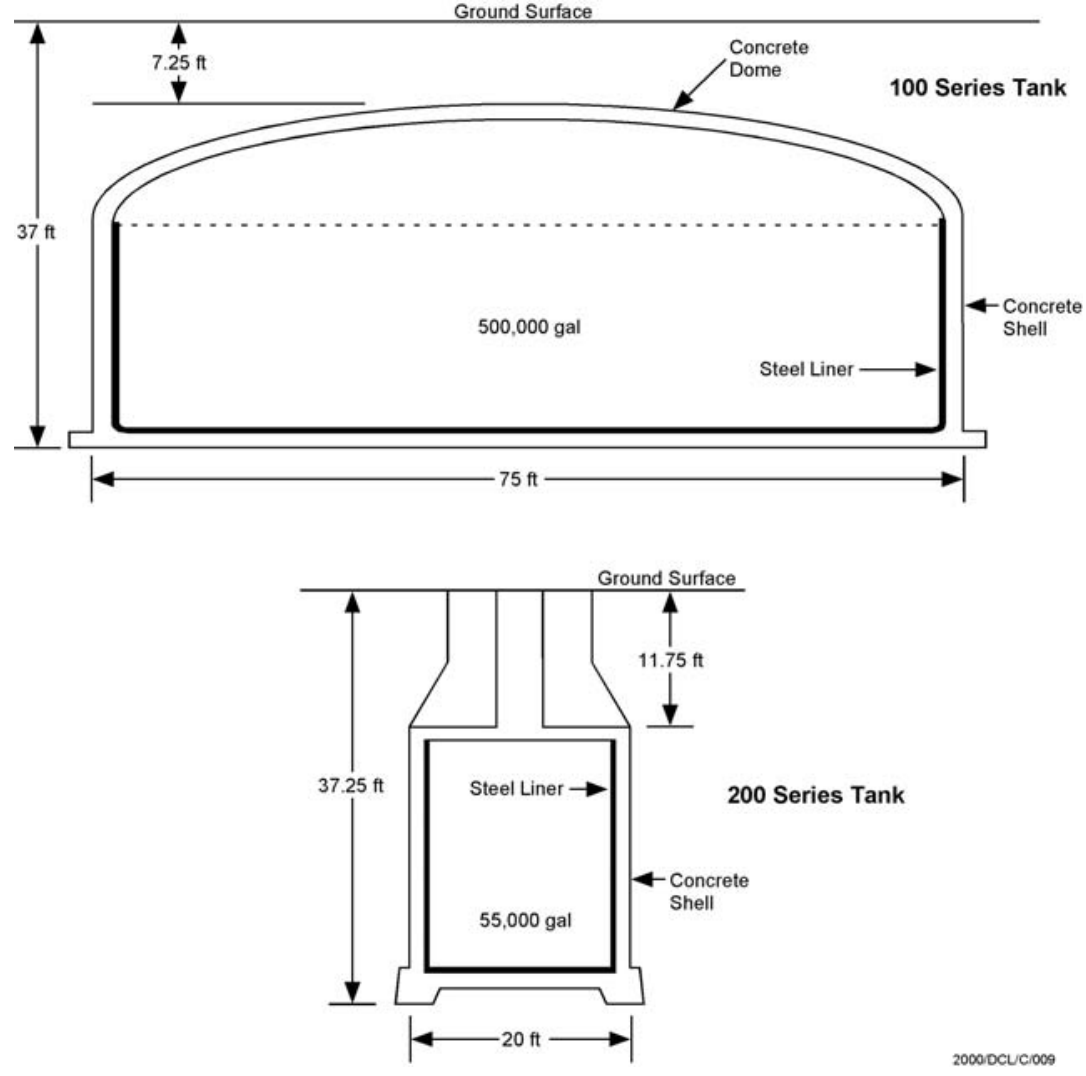

$20000 \mathrm{Cu} \cup \mathrm{Co09}$

Figure 1-1 Schematic of the C-Farm Series 100 and 200 tanks. 


\subsection{HANFORD CLOSURE REGULATORY DRIVER SUMMARY}

\subsection{Overview}

The closure of Hanford Single-Shell Tank farms is governed by a number of regulations and implementing documents:

- Resource Conservation Recovery Act (RCRA) of 1974, as implemented by the Washington Administrative Code (WAC) and Hanford Federal Facility Agreement and Consent Order (HFFACO)

- Atomic Energy Act of 1954 as implemented by Department of Energy Orders.

\subsection{Regulations}

The HFFACO milestone M-45-00 requires retrieval of as much tank waste as possible with tank waste residues not to exceed 360 cubic feet in 100 series tanks or 30 cubic feet in 200 series tanks or the limit of technology whichever is less. Following completion of retrieval the operable units are to be remediated in accordance with approved closure plans.

The Single-Shell Tank System Closure Plan, RPP-13774 [11] was submitted to the Washington State Department of Ecology. RPP-13774 describes waste retrieval, filling of the tanks and closure of the Waste Management Areas. The tank fill is described as three layers (free flowing cementitious grout layer, a structural stability layer, and a high compressive strength layer to deter inadvertent intrusion). The Single-Shell Tank System Closure Plan has not been approved by Ecology at this time. WAC 173-303-610 [12] sets three general performance standards:

1) Minimize the need for further maintenance.

2) Protect human health and the environment (control, minimize, eliminate to the extent necessary post closure escape of dangerous waste, dangerous constituents, leachate, runoff, or dangerous waste decomposition products).

3) Return the land to the appearance and use of surrounding land areas to the degree possible given the nature of the previous dangerous waste activity.

Waste to be land disposed must be treated to meet Land Disposal Restriction (LDR) treatment standards. These requirements are contained in 40 Code of Federal Regulations Part 268 which is required by reference in WAC 173-303-140. However, these standards are concentration based and testing of residuals post treatment (i.e. grouting of the tanks) is not achievable. Therefore a treatability variance from LDR treatment standards is being pursued with "treatment using grout as tank fill” as the basis.

The performance standards are consistent with DOE Order 435.1, Radioactive Waste Management [13] and 10-CFR-61, Licensing Requirements for Land Disposal of Radioactive Waste [14]. DOE Order 435.1 requires preparation of a closure plan as well as performance assessment. DOE Order 435.1 and associated Manual set the following facility requirements and general design criteria:

1. Confinement. Low-level waste systems and components shall be designed to maintain waste confinement. 
2. Ventilation. Design of low-level waste disposal facilities shall include ventilation, if applicable, through an appropriate filtration system to maintain the release of radioactive material in airborne effluents within requirements and guidelines specified in applicable requirements. When conditions exist for generating flammable or explosive concentrations, ventilation systems or other measures shall be provided to keep gases in a non-flammable and non-explosive condition. Where concentrations of explosive or flammable gases are expected to approach the lower flammability limit, measures shall be taken to prevent deflagration or detonation (note that once the tank volume is filled, ventilation would no longer be applicable).

3. Stability. Low-level waste disposal facilities shall be designed to achieve long term stability and to minimize to the extent practical, the need for active maintenance following final closure.

4. Control of water. Low-level waste disposal facilities shall be designed to minimize to the extent practical, the contact of waste with water during and after disposal.

\subsection{Core Functions for Tank Fill Driven by Regulations}

The core functions for tank fill materials can be summarized by the following:

1. Confine residual waste (keep exposure and potential for releases as low as reasonably achievable to protect human health and the environment)

2. Provide stability/minimize maintenance

3. Reduce potential for infiltration or intrusion

4. Constructability

The grout development activities examined grout properties of interest associated with the core functions. These are summarized in Table 2-1. 
WSRC-TR-2005-00195

Revision 0

Table 2-1 Grout properties of interest versus the core functions

\begin{tabular}{|l|c|c|c|c|}
\hline Property & $\begin{array}{c}\text { Confine } \\
\text { residual } \\
\text { waste }\end{array}$ & $\begin{array}{c}\text { Provide } \\
\text { stability/ } \\
\text { minimize } \\
\text { maintenance }\end{array}$ & $\begin{array}{c}\text { Reduce } \\
\text { potential for } \\
\text { infiltration or } \\
\text { intrusion }\end{array}$ & Constructability \\
\hline Flow (for placement in tanks) & $\mathrm{X}$ & $\mathrm{X}$ & & $\mathrm{X}$ \\
\hline Temperature (heat of hydration) & $\mathrm{X}$ & & $\mathrm{X}$ & $\mathrm{X}$ \\
\hline Displacement of debris and waste & $\mathrm{X}$ & $\mathrm{X}$ & $\mathrm{X}$ \\
\hline Shrinkage & $\mathrm{X}$ & $\mathrm{X}$ & $\mathrm{X}$ & $\mathrm{X}$ \\
\hline Cold Joint formation & $\mathrm{X}$ & $\mathrm{X}$ & $\mathrm{X}$ \\
\hline Compressive strength & $\mathrm{X}$ & $\mathrm{X}$ & $\mathrm{X}$ & \\
\hline Fill voids (pipes, risers, etc) & $\mathrm{X}$ & $\mathrm{X}$ & & \\
\hline Bleed water (zero bleed water) & $\mathrm{X}$ & & & \\
\hline Diffusion coefficient & $\mathrm{X}$ & & \\
\hline Reducing environment & $\mathrm{X}$ & & \\
\hline High pH & & & & \\
\hline Design Life (500 year) & & & \\
\hline Period of concern (10,000 year) & & & \\
\hline
\end{tabular}




\subsection{PHYSICAL NATURE OF THE GROUT IN THE TANK}

\subsection{Placement Properties}

The three grout design mixes were developed to meet single shell tank placement requirements. These requirements include, high flowability, self-consolidation (i.e., does not require the use of vibration to enhance flow for placement), lack of segregation (settling of particles from the water) and no bleed water.

\subsection{High Flowability and Self-Consolidation}

The grout mixes developed for Hanford single shell tank closure are highly fluid mixes that are self-consolidating (also referred to as self-compacting). The high fluidity and self-consolidation properties are important for placement of the grout into the tanks [15]. It ensures that grout, placed through a central riser, will flow out in all directions, reach the walls of the tank, and completely fill the tank without creation of voids. From another point of view, the single shell tank can be viewed as a form that is completely filled by placement of the self-consolidating grout mixes.

This high flow property of the grout is achieved through addition of (1) admixtures (a superplasticizer and a viscosity modifier/thickener) and (2) fine aggregate in the mixes. The rheological properties of the fresh grout control the flow and self-consolidating nature of the mixes during placement. A low viscosity mix ensures that the grout will flow through or around obstacles such as reinforcement that is frequently used in normal building construction. In single shell tank closure, obstacles can include any equipment that remains in the tank as well as the residual waste itself. Self-consolidation on the other hand depends on a low yield stress for the mix.

The required flow properties were met for all three mixes despite the differences (see Section 9) in the relative ratios of the binders in the design mixes. (The binders in the design mixes are portland cement, fly ash and ground, granulated blast furnace slag.) The total binder content (660 lbs/cyd) and the amount of sand (2,530 lbs/cyd) were held constant for all three mixes. Therefore, placement properties are essentially independent of the layer (stabilization, structural and capping) being poured.

Scale-up testing demonstrated that these mixes can flow a distance of $40 \mathrm{ft}$ at the projected placement rate of 60 to $90 \mathrm{cyd} / \mathrm{hr}$. Since the largest tanks have a diameter of $\sim 75 \mathrm{ft}$, placement through a central riser in the large tanks should result in a completely filled single shell tank. For the smaller tanks, filling through an off-center riser is an option.

\subsection{Segregation and Bleed Water}

The design of a grout mix for single shell tank closure must balance the desired high flowability requirement against the detrimental effects of segregation and bleed water. Additional flowability of a mix can be achieved through the use of higher water content and admixtures. 
However, higher water content generally leads to a more rapid settling of the particles (segregation) and formation of bleed water. Therefore, the design mixes for the three layers have operating regions or windows for which flow and bleed water requirements for the mixes are met. These windows had to be experimentally determined.

From the results of bench scale testing, a range of water content for each mix was developed that corresponded to a flow per ASTM D-6103 of 12 to 15 inches. The inclusion of this water range in the grout specifications [1] is intended to provide guidance and latitude to the operator of the grout batch plant such that a highly flowable grout that completely fills the tank without segregation and bleed water can be produced.

\subsection{Residual Waste}

Prior to placement of the grout in the tank, the maximum practical amount of the sludge is removed from the tank. In general this translates to a volume of residual waste less than $360 \mathrm{ft}^{3}$ or 2,693 gallons in 100 series tanks or less than $30 \mathrm{ft}^{3}$ or 224 gallons in 200 series tanks. This volume of residual waste in a 100 series tank is equivalent to approximately a 1 inch layer over a $75 \mathrm{ft}$. diameter circle. However, the actual distribution of the residual waste in the tank will be determined by the geometry of the dished bottom, nature of the residual waste, and the cleaning processes employed.

In general terms, the physical and chemical properties of the residual waste will vary from tank to tank. There may be a range of particle sizes for the insoluble waste components from large 'aggregated' pieces down to the micron sized particles normally characteristic of single shell sludge. The supernate and/or wash water will be a very dilute solution of salts with a low concentration of radionuclides due to the cleaning and washing cycles that are and will be performed to remove the sludge. The $\mathrm{pH}$ of the supernate will be adjusted to be greater than 8 to control corrosion of the tanks.

\subsection{Placement of the Stabilization Layer}

As discussed previously, the grout mixes used to fill the tank have been designed to have very high flow and consequently high water content. Therefore, the grout has a low capacity to absorb additional water (i.e., the supernate or wash water). When the grout is added to the tank, the less dense supernate may be displaced upwards by the mix and end up on top of the freshly poured grout.

It is necessary to have a process to solidify this supernate if it is present and not absorbed by the fresh grout layer. This supernate layer will contain radionuclides and the intent is to isolate the radionuclides in the stabilization layer. This is done by adding a dry mix of portland cement, fly ash, and blast furnace slag to the tank. This dry material reacts hydraulically with the water in the supernate to produce a solid grout layer. The scale-up testing in a swimming pool simulated this process of supernate displacement to the top of the grout layer followed by solidification through addition of a dry mix [3]. 
The decision to add a layer of dry mix will be made during tank filling operation based on whether a liquid layer is present. The formation of a liquid layer in any given tank will depend on the amount of free supernate, the water content and water absorptive capacity of the mix, the fill schedule, and the volume of stabilization grout added. The operator has the latitude to place additional dry mix layers if necessary in those cases where insufficient dry mix was added to solidify all of the supernate. Following solidification of the supernate, an additional layer of stabilization grout may be added.

As noted above, the nature of the residual solid waste can be highly variant depending on a number of factors. For the scale-up testing, both physical and chemical simulants were added to the two swimming pools before addition of the stabilization grout. The chemical simulants were developed based on oxalate cleaning and washing for C-106 and on sample data for C-200 series tanks [3]. The physical properties of the C-106 and 200 series heels were simulated with several types of inert materials, such as, 1.5 inch gravel, 0.25 to 0.375 inch pea gravel, sand, clays and soil placed in piles about 20 inches in diameter on the bottom of the pool. In the case of the C200 series tanks, sludge particulates were simulated with precipitated aluminum hydroxide.

The very fine precipitated aluminum hydroxide particles from the C-200 simulant moved outward toward the edges of the tank as the stabilizing layer was introduced. Observation of the bottom of the stabilizing grout after one week of curing demonstrated that the particles were isolated and covered but not encapsulated by the grout. That is, the bottom of the cured grout was white in the places where this solid was present.

The finer piles of sand were also covered by the grout and not encapsulated. As with the aluminum hydroxide particles, the grout was unable to penetrate the interstitial regions of the fine particulates but instead flowed over the top of these piles. The end result is one of isolation of the fine particles by sandwiching these particles between the bottom of the swimming pool and the bottom of the first grout layer.

For the coarser particles, the grout was able to penetrate the interstitial regions and more thoroughly, but not necessarily completely, encapsulate them.

\subsection{Placement of the Structural and Capping Layers}

The structural layer makes up the largest volume of fill material and prevents subsidence. This layer is followed by the capping layer of higher compressive strength as a warning system to an inadvertent intruder in the future. Both of these grouts have flow characteristics which can be tuned to essentially the same values as that of the stabilization grout. That is, the grout will flow around, through, or into equipment (depending on the size of the opening) or other obstacles left in the tank and will flow to the edges of the tank to ensure complete filling without voids.

\subsection{Cured State}

After placement the grout will continue to harden with time due to the ongoing but diminishing hydraulic reactions. These hydration reactions can go on for months before a final set is achieved. Changes in the structure of the cured monolith with time are discussed in Section 7 of this report. 


\subsection{REQUIRED GROUT PROPERTIES - FRESH}

\subsection{Level 2 Specifications}

The Level 2 Specifications for the first five C Farm tanks [16] and the first two S Farm tanks [17] that are scheduled to be closed first, identify the following requirements for fresh properties of grout:

- All three grout layers shall be flowable (>12 inch flow) as determined by ASTM D6103

- All three grout layers shall have no bleed water

- The residual waste shall be stabilized by the stabilization layer

The grout design mixes for all three layers were developed based on a flow greater than 12 inches (ASTM D6103) with no bleed water. Therefore, the first two fresh grout Level 2 Specifications are met by the design mixes specified in the Hanford Grout Specifications for High-Level Waste Tank Closure [1].

Stabilization of the residual waste by placement of the stabilization layer is accomplished in part by isolation and covering of the residual solid waste through the interaction of the waste with the fresh grout (see Section 3). The liquid supernate will also be isolated in the stabilization layer. Free liquid such as supernate that is displaced by the grout will be absorbed by dry grout mix. Further stabilization is afforded by the reductive nature of the fresh stabilizing grout. This additional stabilization is part of a defense in depth strategy that is discussed in Section 6.

\subsection{Treatability Variance Requirements}

The fresh properties of concern for a Treatability Variance are encapsulation/covering of the solid waste and formation of a monolithic structure.

At a minimum, the grout will cover the solid residual waste and will encapsulate at least partially the solid particles (see discussion in Section 3).

The flow properties of the waste will lead to a completely filled tank without voids that in turn will lead to a monolithic structure if there are not significant interruptions in grout placement. In the scale-up testing, subsequent layers placed into the swimming pool one day later still resulted in bonding between the two layers. This bonding was evident due to the difficultly associated with breaking up the monolith after only one week of curing time. On the other hand, the weakest point was along the horizontal interface between the two layers as demonstrated by their separation after being rammed by a dozer blade from the side (see Section 9). The time dependence (in terms of pour interruptions) of bonding between layers was not specifically tested in this task. 


\subsection{REQUIRED GROUT PROPERTIES - CURED}

\subsection{Level 2 Specifications}

The Level 2 Specifications for the first five C Farm tanks [16] and the first two S Farm tanks [17] that are scheduled to be closed first, identify the following requirements for cured properties of grout:

- Compressive strength of the stabilization and structural layers shall be >50 psi

- The mobility of key contaminants of concern in the stabilization layer shall be controlled or minimized

- All three grout fill materials and their placement shall be designed to mitigate cold joint formation

- The structural layer shall provide long term structural stability and prevent subsidence

- Compressive strength of the capping layer shall be $>2,000$ psi

- The design life for the capping layer shall be 500 years

- There shall be a maximum $250^{\circ} \mathrm{F}$ dome temperature during and after filling of the tanks

- There shall be a maximum $10^{\circ} \mathrm{F}$ through wall temperature gradient during and after filling of the tanks.

- There shall be a maximum allowable hydrostatic pressure equivalent to 185 inches of a liquid with a specific gravity of 2.0 for 241-C-106.

- There shall be a maximum allowable hydrostatic pressure equivalent to 280 inches of a liquid with a specific gravity of 2.0 for 241-C-200 Series Tanks

- There shall be a maximum allowable hydrostatic pressure equivalent to 275 inches of a liquid with a specific gravity of 2.0 for 241-S-102 and 241-S-112

- The tanks shall be isolated to prevent transfer of fill material to an adjacent tank.

The compressive strengths of the three grout materials readily meet the requirements of $>50 \mathrm{psi}$ for the stabilization and structural grouts and $>2,000$ psi for the capping grout. In fact, the compressive strength after 90 days was $~ 3,500$ psi for the stabilization grout and $\sim 3,900$ psi for the capping grout.

Control and/or minimization of the key contaminants of concern by placement of the stabilization layer is partially addressed by the hardening of the grout once it has flowed over and around the residual waste as detailed in Section 3. Therefore, to the extent that the radionuclides from the residual waste are isolated in the stabilization layer, there is control of the mobility of key contaminants of concern. Additional control of mobility is accomplished through a reducing environment in the stabilization layer. This control is part of defense in depth strategy that is discussed in Section 6.

Mitigation of cold joint formation (the interfacial area between two consecutive pours separated in placement time) will be controlled through the placement schedule. No specific effort was made to develop a grout formulation that would mitigate cold joint formation. Section 7 provides observations on cold joints between consecutive pours. 
The structural layer provides for structural stability and will prevent subsidence simply by filling the bulk of the tank with a grout that has a compressive strength greater than $50 \mathrm{psi}$. In fact, the bench scale testing revealed a 90 day compressive strength of this material that is greater than 1200 psi.

The design life requirement of 500 years for the capping grout is based on 10CFR61. The estimate for the life time of the grout is expected to be much greater than this based on (1) consideration of ancient grouts, (2) calculation of grout stability and (3) by consideration of the entire closed tank system. Ancient concretes and mortars are discussed in Section 8 and reveal the exceptional longevity of ancient concretes (and grouts) and mortars. A calculation of grout longevity at the SRS E-Area Vaults estimated minimum lifetime of 1,000 years [18]. Although there is not a direct correlation with grout in a single shell tank to the E-Area Vault, the estimate nevertheless, indicates the long period over which grout can be stable. Finally the capping grout is protected by a reinforced concrete tank dome (the dome has limited penetrations for risers and manholes which can be filled as well) and a modified RCRA Subtitle C Barrier which has a design life of 500 years [19]. Infiltration of water is significantly reduced by this RCRA Subtitle $\mathrm{C}$ Barrier to a level of $0.5 \mathrm{~mm} /$ year. The degradation of the capping layer by water is therefore considerably mitigated. An inadvertent intruder drilling into the capping layer will still meet with resistance from both the steel reinforced tank dome and the high compressive strength grout.

Compliance with the temperature requirements for the tanks depends on the heat of hydration of the mixes and the rate of placement. SRNL performed adiabatic temperature rise measurements (Section 9) and provided these results to ARES Corporation (Architectural Design Agency for the Tank Closure Fill System) who calculated temperature profiles as a function of placement rates assuming conservative values. The adiabatic temperature rise measurements confirmed that the ARES assumptions were conservative. ARES also addressed the issue of hydrostatic pressures in the tanks.

The transfer of grout through a cascade line was addressed in scale-up testing (Section 10). Test results indicated that control of the grout flow can lead to sealing of the cascade lines during placement and thereby preclude transfer of grout into an adjacent tank.

\subsection{Requirements for Long Term Risk Analyses}

Long term risk analyses are needed in order to close the tanks. The modeling approach in such analyses will likely use a diffusion-based release of Tc-99 that is independent of the oxidation state of the technetium. The important cured properties for such release modeling are the diffusion coefficient and the hydraulic conductivity. Also important for such modeling is the durability of the grout.

The measurement of the effective diffusion coefficient was determined for binder samples using Tc-99 at Sandia National Laboratories. This value is presented in Section 9. The hydraulic conductivity was also measured for several of the grout formulations and their values are 
presented in Section 9. Physical and chemical properties of the grout can change with time. Section 7 describes such durability changes.

\subsection{Treatability Variance Requirements}

The cured properties of concern (encapsulation/covering of the solid waste, formation of a monolithic structure, and low shrinkage) may affect the treatability variance.

At a minimum the grout will cover the solid residual waste, encapsulate at least partially the solid particles, and then solidify with time (see discussion in Section 6). After filling the tank, the grout will essentially be a solid monolithic structure. Some cracking may occur with time and cold joints may or may not be present. If a horizontal cold joint occurs with only minimal binding between the two layers, the mass above this joint will keep the interface region in compression.

The shrinkage of the stabilization and structural mixes were measured for samples that were cured for 28 days with a result of $\sim 0.005 \%$ shrinkage. This percentage translates, for example, into a change in length over $75 \mathrm{ft}$ (diameter of C-106) of $\sim 4$ mils (4/1000 of an inch). See Section 9 for actual values for shrinkage. 


\subsection{IMMOBILIZATION OF TECHNETIUM}

Filling of single shell tanks with grout as part of the tank closure process must provide protection to the ground and surface water resources. From a radionuclide perspective, Tc-99 is often the most important isotope in the residual tank waste. Therefore, the dose at the tank farm fence line determined through long term risk analyses is often dominated by Tc-99. Computer simulations are carried out for 10,000 years. This long period of time requires a model to predict the parameters important to the performance objective (e.g., beta/gamma dose at the tank farm fence line) both spatially and temporally. The approach being considered for Hanford modeling of these parameters over 10,000 years has been detailed in a report by Khaleel et al [10]. Once out of the tank, the migration of these species (radioactive and non-radioactive) will be predicted using flow and transport modeling through the Vadose Zone to the ground water [10].

\subsection{Pertechnetate $\left(\mathrm{TcO}_{4}{ }^{-}\right)$}

Technetium-99 (Tc-99) is an important radionuclide in tank residual waste. This is due to the pertechnetate anion $\left(\mathrm{TcO}_{4}{ }^{-}\right)$which is the stable chemical form of Tc-99 (half-life of 213,000 years) in aerobic conditions and is a highly soluble and mobile species [15, 20]. Therefore, the pertechnetate anion can be released from the tank into the environment and be an important contributor to the overall dose at the fence line.

The current modeling approach for Hanford calculates the dose due to Tc-99 at the fence line over 10,000 years by conservatively assuming that all of the technetium is present as the pertechnetate anion. However, technetium can exist in several oxidation states and the reduced form is significantly less mobile than the oxidized, pertechnetate form.

\subsection{Reduction and Immobilization}

Pertechnetate has a VII oxidation state which can be reduced to the IV oxidation state resulting in an insoluble precipitate. It has been known for some time that pertechnetate can be reduced to the immobile Tc(IV) state by using blast furnace slag in grout or concrete mixes [15, 21, 22]. Shuh et al. [23] have used Extended X-ray Absorption Fine Structure (EXAFS) and X-ray Absorption Near Edge Spectroscopy (XANES) to investigate the oxidation states of technetium and the reduction of pertechnetate by slag in grout mixes as well as the re-oxidation.

The inclusion of blast furnace slag in the Hanford grout design mixes therefore, provides a reductive source to produce and maintain the Tc(IV) species. This strategy of chemical reduction and immobilization of Tc(VII) in the single shell tanks at Hanford provides an additional layer in the defense in depth strategy to mitigate Tc-99 release to the environment.

A Tc(IV) species, solubilized by an organic complexant, has been identified in certain tanks at Hanford [23]. Slag will most likely not react with this species because the technetium in this complex is already reduced to the (IV) state. However, this was not experimentally verified. Because this complexed Tc(IV) species is present in the supernate, and because the supernate 
will be significantly diluted during cleaning and retrieval, it will most likely not be a major contributor to the dose at the tank farm fence line.

\subsection{Re-oxidation of Reduced Technetium}

The reduction of pertechnetate to the Tc(IV) state is a reversible reaction, i.e., the Tc(IV) state can be oxidized back to the (VII) pertechnetate state. Therefore, infiltration of oxidizing species into the grout matrix over time can oxidize Tc(IV) back to the mobile pertechnetate species. Shuh et al. [23] have shown that oxygen is the key oxidant in this re-oxidation step.

The major infiltration mechanism for oxygen into the grout is by oxygen diffusion through the water within the grout pores. Infiltrating water can supply additional oxygen as the oxygen is depleted through the re-oxidation reaction. Typically water contains dissolved oxygen at $\sim 9$ $\mathrm{mg} / \mathrm{L}(9 \mathrm{ppm})$. In order to maintain the immobilization of technetium as Tc(IV) in the tank, the infiltration of oxygen into the grout and the resulting re-oxidation of Tc(IV) must be limited.

For durable, slag-containing grout, oxygen infiltration is a slow process occurring mainly through diffusion. Therefore, oxygen infiltration in a durable grout matrix by diffusion will be slow over tens of thousands of years [24] and penetrate only on the order of centimeters over 10,000 years. However, a breakdown of the grout through chemical degradation or by cracking can lead to greater water and oxygen infiltration through advection. This in turn can lead to an increase in the oxidation of Tc(IV).

The mitigation of Tc(IV) oxidation can be accomplished through placement of an engineered barrier layer, good grout durability, and inclusion of excess reductant in the grout mixes. This development work focused on (1) design formulation of grouts that are expected to be durable under these conditions and (2) incorporation of blast furnace slag, the source of reductant, into all three layers of grout. (Excess reductant will react with incoming oxygen and reduce the reoxidation of Tc(IV).)

\subsection{Tc-99 Sorption and Leaching Tests}

A series of Tc-99 sorption, desorption and leaching experiments were performed using cured grout samples in a collaborative effort between SRNL and Sandia National Laboratory [4]. The purpose of this work was to determine the interaction of slag in the grout mix with Tc-99. The testing was broken down into two separate types of experiments:

Leaching. These tests included the incorporation of Tc-99 into the binder mix, curing of the samples for 28 days, and measurement of the leaching of Tc-99 from both monolith and crushed samples.

Sorption and Desorption. These tests included the preparation of non-radioactive grout mixes, curing of the samples for 28 days, grinding to a fine powder, exposure to Tc-99 in solution, and measurement of Tc-99 sorption and desorption over time. 


\subsubsection{Monolith Leaching Tests (Tc-99)}

The Tc-99 monolith leaching was performed to determine how effectively the Tc-99 is bound by the binder materials after curing. (In this testing, only the binder materials - portland cement, blast furnace slag, and fly ash were used to prepare the samples. The fine sand was excluded.) These tests used $30 \mathrm{~mL}$ monolith samples (see Figure 6-1 for general shape of the monoliths) that were leached as monoliths according to a modified ANSI/ANS 16.1 accelerated test protocol [25]. The samples were placed in $500 \mathrm{~mL}$ Teflon leach vessels with $~ 300 \mathrm{~mL}$ of deionized water per the ANSI 16.1 protocol (Figure 6-2). The solutions were analyzed for Tc-99 at leach intervals of 30 seconds and 2, 7, 24, 48, 120, and 624 hours.

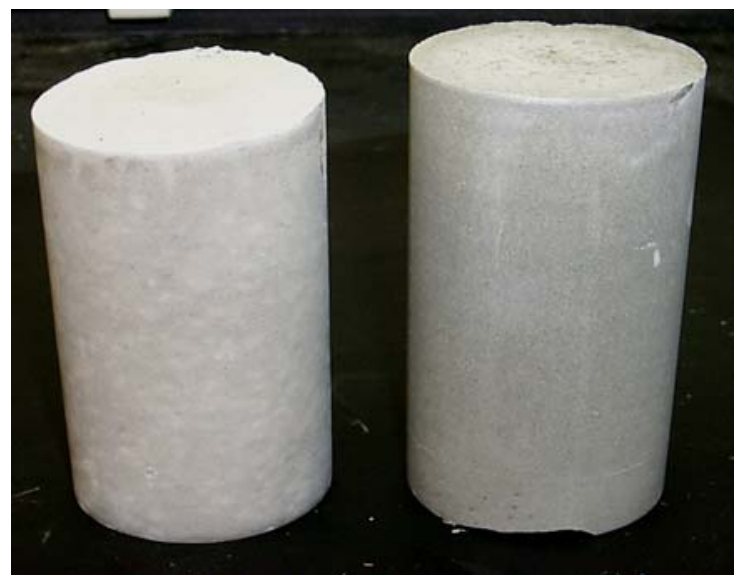

Figure 6-1 Photograph of large ( $\sim 80 \mathrm{~mL})$ monoliths prepared for the sorption and desorption testing. For the monolith leaching tests, the monoliths were similar in shape except that they were $30 \mathrm{~mL}$ in volume. 

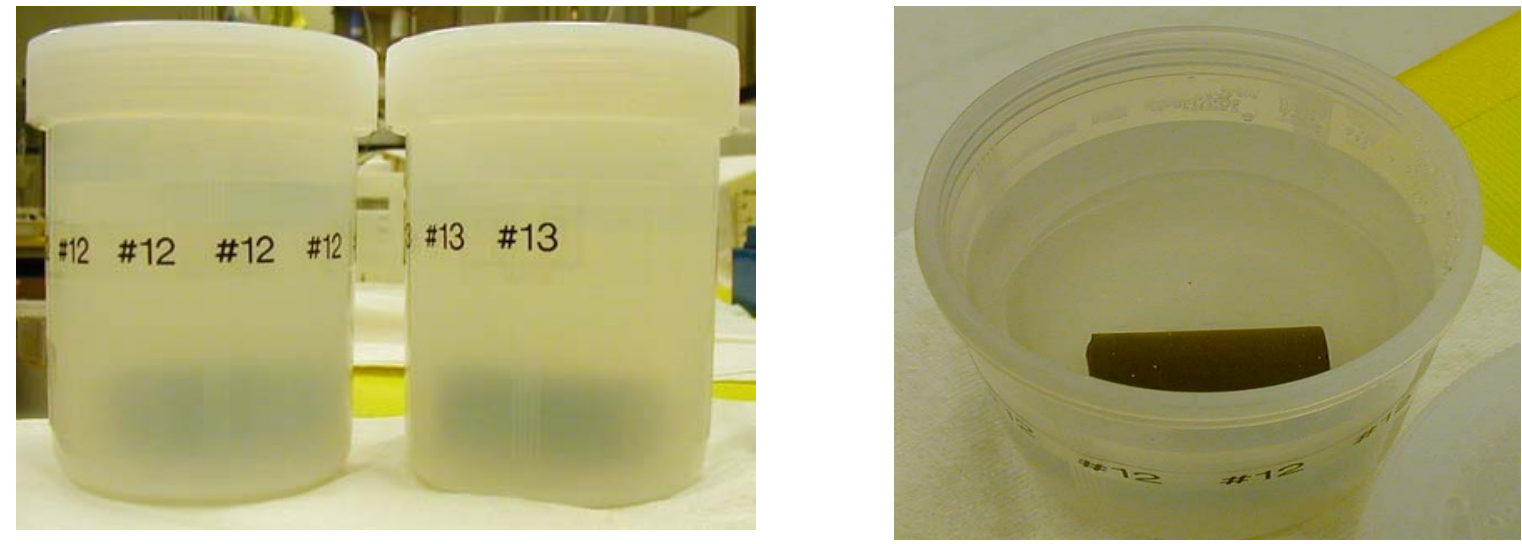

Figure 6-2 The first photograph shows monolith leaching with the $30 \mathrm{~mL}$ cylinders in the 500 $\mathrm{mL}$ Teflon vessels. The second photograph shows the vessel immediately after placement of the monolith and prior to capping the vessel.

The ingredients and compositions of the samples used in the monolith leaching tests are provided in Table 6-1. For these tests three different Tc-99 spiked liquid phases were used: (1) deionized water (DIW), (2) C-106 simulant and (3) C-200 simulant.

Table 6-1 Binder ingredients and amounts for samples used in the monolith and crushed leaching tests.

\begin{tabular}{|l|c|c|c|}
\hline Ingredient & $\begin{array}{c}\text { Binder } \\
\mathbf{1 2}\end{array}$ & $\begin{array}{c}\text { Binder } \\
\mathbf{1 3}\end{array}$ & $\begin{array}{c}\text { Binder } \\
\mathbf{1 6}\end{array}$ \\
\hline Tc-spiked DIW & $360 \mathrm{~mL}$ & --- & --- \\
\hline Tc-spiked C-106 & --- & $400 \mathrm{~mL}$ & --- \\
\hline Tc-spiked C-200 & --- & --- & $500 \mathrm{~mL}$ \\
\hline Cement & $115 \mathrm{~g}$ & $115 \mathrm{~g}$ & $115 \mathrm{~g}$ \\
\hline Slag & $320 \mathrm{~g}$ & $320 \mathrm{~g}$ & $320 \mathrm{~g}$ \\
\hline Fly ash & $570 \mathrm{~g}$ & $570 \mathrm{~g}$ & $570 \mathrm{~g}$ \\
\hline Kelco-Crete ${ }^{\circledR} /$ ADVA $^{\text {TM}}$ Flow & $2 \mathrm{~mL}$ & $2 \mathrm{~mL}$ & $2 \mathrm{~mL}$ \\
\hline Water/Binder Ratio & 0.358 & 0.390 & 0.423 \\
\hline
\end{tabular}

Monolith leaching tests revealed Tc-99 leaching values at or near the sensitivity of the measurement equipment. Effective diffusivities and Leach Indices for Tc-99 for these cured monolithic samples were calculated from the leaching data.

Calculations of the Leach Indices [25] for each binder sample (ANSI/ANS 16.1) using measured values of the Tc-99 concentrations resulted in Leach Indices ranging from 10.4 to 11.4. The 
range of Leach Indices using plus/minus 2 sigma values for the Tc-99 concentrations gave an overall range of values for the Leach Indices from 9.2 to 14.2 (at the $95 \%$ confidence interval).

The range of the effective diffusivities using measured Tc-99 values plus/minus 2 sigma values for the Tc-99 concentrations gave an overall range in $D_{\text {eff }}$ from $1.1 \mathrm{E}-09$ to $1.1 \mathrm{E}-14 \mathrm{~cm}^{2} / \mathrm{sec}$ (at the $95 \%$ confidence interval).

For direct comparison, Hanford uses a $\mathrm{D}_{\mathrm{eff}}$ of $5.0 \mathrm{E}-10 \mathrm{~cm}^{2} / \mathrm{sec}$ for their risk assessments [26].

\subsubsection{Crushed Monolith Leaching Tests}

A second set of Tc-99 spiked binder samples was prepared for Tc-99 leaching/extraction tests per a modified ASTM D-5233, Single Batch Extraction Method for Wastes. These crushed leaching tests accelerate the leaching of Tc-99 compared to monolith samples due to the increased grout surface area.

The cured binders were crushed to approximately $2 \mathrm{~mm}$ sized particles. Three grams of the crushed material from each binder were placed in a 35-mL centrifuge tube. The extraction fluids (leachates) consisted of $30 \mathrm{~mL}$ of DIW, C-106 simulant, or C-200 simulant. Leachates were sampled and analyzed for Tc-99 after 1, 5 and 27 days. Small amounts of each leachate were removed from the centrifuge tubes with a syringe at each interval and filtered through a $0.45 \mu \mathrm{m}$ nylon filter. Duplicate 1-mL samples of filtered leachate were collected for each leach interval. Figure 6-3 illustrates the crushed samples in the leaching solution.

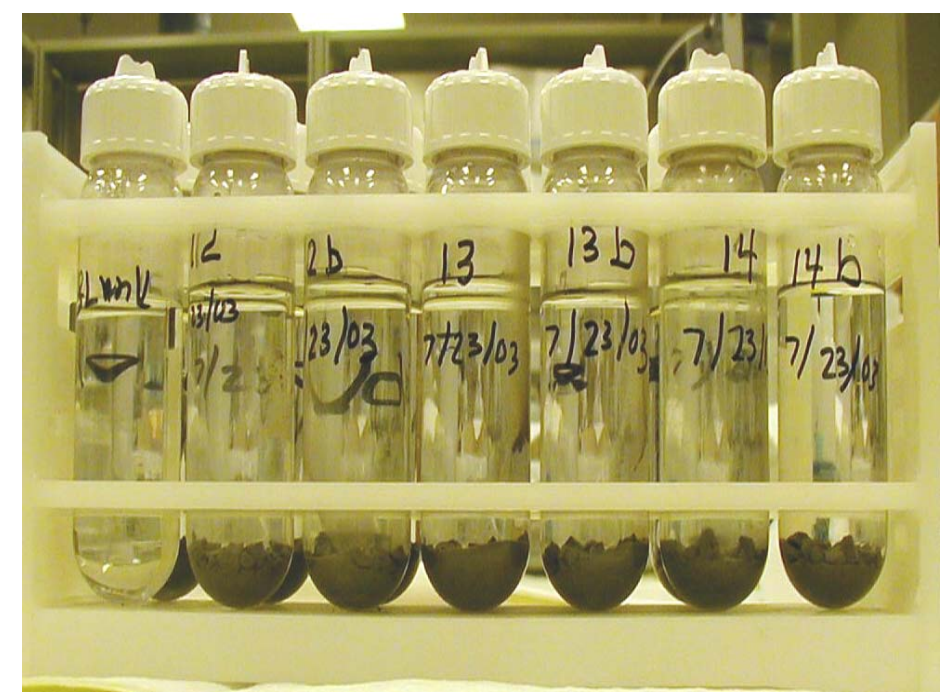

Figure 6-3 The samples for the crushed monolith leaching tests. Each sample contained 3 grams of crushed sample in $30 \mathrm{~mL}$ of leachate (the blank is on the far left).

The results of the crushed monolith leaching tests in deionized water revealed that the maximum amount of Tc-99 leached from the sample was 3\% of the total Tc-99 content, and this value peaked at the first measurement time of 1 day. Interestingly, the amount of Tc-99 in solution 
then decreased over the next 26 days to approximately $25 \%$ of the value observed at day 1 . This decrease in Tc-99 with time is most likely a reflection of the re-precipitation of Tc(IV) on the blast furnace slag at or near the surface of the crushed samples.

\subsubsection{Tc- 99 Sorption and Desorption Tests}

Tests were performed to evaluate sorption of Tc-99 onto crushed, cured binder samples followed by leaching or desorption of the sorbed Tc-99 from these samples. The sorption part of the test was performed according to a combination of the ASTM D-4646, 24-Hour Sorption Test, and ASTM D-4319, Short-Term Batch Sorption Test, protocols. The desorption part of the test was performed on the binders after a total of 5 days exposure to the Tc-99 spiked solutions, according to a modified ASTM D-5233 extraction test. The solutions were spiked to $2.5 \mathrm{E}+04 \mathrm{pCi} / \mathrm{mL}$ Tc99.

These tests revealed that significant Tc-99 sorption from the liquid phase occurred over the 5 day period of sorption. Tc-99 sorption was greater for the C-106 and C-200 Tank supernates simulants than for deionized water. With the C-200 simulant, 87\% of the Tc-99 was removed and with the C-106 simulant, 95\% of the Tc-99 was removed from the solution versus 37\% removal of Tc-99 for deionized water.

Following sorption, the solid samples were separated from the solution, washed and then placed in $30 \mathrm{~mL}$ of solution that did not contain Tc-99. Desorption was followed over 20 days with samples taken and analyzed for Tc-99 at 1, 5, and 20 days. As with sorption of Tc-99, desorption depended on the leachate salt concentration (deionized water, C-106 and C-200 simulants).

For deionized water, approximately half of the Tc-99 was released after 20 days whereas the corresponding values for C-106 and C-200 simulants were 10\% and 20\%.

\subsection{Pertechnetate Reduction in Hanford Tank Closure}

The reduction of pertechnetate is important in tank closure as part of the defense in depth strategy to mitigate Tc-99 release to the environment. The following discussion addresses pertechnetate reduction as it applies to the supernate and solids in the residual waste remaining in the tank prior to filling with grout.

\subsubsection{Tank Supernate}

Based on retrieval of waste from tank C-106, the amount of supernate left in the tank will be small $\left(\sim 10 \mathrm{ft}^{3}\right)$ and significantly diluted due to washing. Nevertheless, some technetium will be present in the supernate. The results from the leaching tests revealed that the pertechnetate anions in solution will interact with the surface of the blast furnace slag, be reduced to Tc(IV), and form an insoluble precipitate. During tank filling with grout, the supernate from the residual tank waste will come into intimate contact with the blast furnace slag from either the fresh grout mix or the dry top dressing. Therefore, this process of reduction and precipitation will occur for pertechnetate in the tank supernate during placement of the stabilization grout layer. 
In addition, any pertechnetate left on the tank walls or equipment that is at a height above the stabilization layer, may solubilize when the fresh liquid grout is placed in the tank. This solubilized Tc-99 will then be immobilized by the slag which is present in both the structural and capping mixes.

As long as oxygen infiltration is controlled at a low rate, the reduced technetium originally in the supernate will remain insoluble and prevented from entering the environment.

\subsubsection{Residual Tank Solids}

The reduction and immobilization of pertechnetate in the residual tank solids is more complex than in the supernate. This complexity for the residual tank solids arises from (1) the presence of multiple oxidation states of the technetium in the solid particles, (2) additional stability of the solid particles (resistance to dissolution and leaching), and (3) the presence of a range of coverage of the particles by grout.

\subsubsection{Oxidation State of Technetium in Residual Solid Waste}

The technetium in the solid particles can exist in either the reduced (IV) state or the oxidized state (pertechnetate) and be trapped (encapsulated) in the particles. For the pertechnetate in these particles to be released to the environment, the solid particles must first start to dissolve and then release the trapped pertechnetate to the grout matrix. Migration out of the tank can then occur by the process of diffusion or advection. However, as shown in the Tc-99 sorption tests (Section 6.4.3) the pertechnetate can then be reduced and immobilized by reaction with the blast furnace slag in the cured grout.

As dissolution of the particles occurs (and this process will only occur after sufficient water can infiltrate the matrix), reduced Tc(IV) will also be exposed. This species must next be oxidized by oxygen in order to convert it to the mobile pertechnetate species before it can be available for release to the environment.

\subsubsection{Leaching Tests on C-203, C-204 and C-106 Residual Waste}

A study was carried out by Deutsch et al. [27] from the Pacific Northwest National Laboratory on the leaching of Tc-99 and dissolution of other chemical and radioactive species from solid residual waste sampled from C-203 and C-204. These studies revealed that there is a highly soluble form of technetium (pertechnetate) and an insoluble and inaccessible form of technetium in the particles. Since these samples were taken in 2003 prior to waste removal from the tanks, the highly soluble pertechnetate had yet to be removed in the washing/removal process. Deutsch et al. [27] suggest that the intractable technetium is incorporated into a very insoluble iron mineral, assumed to be ferrihydrite $\left[\mathrm{Fe}(\mathrm{OH})_{3}\right]$.

Deutsch et al. [28] have also studied a residual waste sample taken from C-106 in January of 2004 after the tank had been treated with oxalic acid and neutralized with sodium hydroxide. 
The results are consistent with the findings for the C-200 tanks. The fact that these samples were taken after oxalic acid and water washing reduced the water soluble technetium to 2 to $3.5 \%$ of the total technetium present in C-106.

These results provide quantitative release rates of Tc-99 for tank residual solids that can be incorporated into the modeling efforts. This inclusion will acknowledge the stability of these particles in the presence of infiltrating water and consequently, the retardation of Tc-99 release to the environment.

\subsubsection{Grout Encapsulation of Residual Solid Waste}

As discussed in Section 3, the residual solid particles in the tank will have various levels of coverage by the stabilization grout. The smaller particles that can be displaced upward by the incoming grout will essentially be completely encapsulated by the grout. Scale-up testing at Savannah River Site revealed that some of the larger particles (simulated by sand, gravel etc) on the bottom of the tank will be covered but not completely encapsulated by the grout.

Those particles that are not completely encapsulated by grout will have part of their surface directly available for interaction with water and oxygen. (This will occur only when water has been able to infiltrate the basemat and carbon steel lining of the tanks.) In this case, the leaching tests performed at PNNL on Tank C-106, C-203, and C-204 samples of residual tank waste solids reveals a stability that can significantly retard the release of Tc-99 to the environment.

For those particles that are completely encapsulated by the grout, the grout matrix will provide a barrier to oxygen and water infiltration as discussed above for the supernate. 


\subsection{GROUT DURABILITY}

\subsection{Introduction}

The American Concrete Institute has defined concrete (grout) durability as its resistance to weathering action, chemical attack, abrasion, and other degradation processes. Therefore, grout durability is a measure of the longevity of the grout. A very stable structure that does not change over time is said to have good durability. In Section 8, a discussion of ancient concrete and mortar structures is presented demonstrating that even under weathering and abrasive conditions, concrete (grouts) and mortars can last for thousands of years with very little loss of structure.

In relation to tank closure, the durability of grout is important (1) for the lifetime requirement (a minimum of 500 years) of the capping layer, (2) the release of Tc-99 from the grout into the surrounding soil, and (3) in controlling water infiltration in general throughout the tank. A consideration of the possible mechanisms for grout degradation, as presented below, reveals that no credible degradation mechanisms appear feasible for the grout placed in Hanford single shell tanks.

\subsection{Monolith Formation}

During the placement of grout into a single shell tank (e.g., 241-C-106) the tank structure itself (concrete and carbon steel liner) acts as a form into which the grout is poured. If the placement is not significantly interrupted and if the grout mixes meet the placement (fresh) specifications, the result will be a large monolith.

The amount of grout required to fill a single shell tank and produce this monolith is quite large. For example, roughly 14 million pounds (6,900 tons) of grout must be placed in Tank 241-C-106 in order to fill the tank completely. To put this in perspective, this amount of grout corresponds to over 500 truckloads from a Ready Mix Company assuming an average load of 8 cyds grout/truck. (During actual filling of the single shell tanks with grout, an onsite batch plant will be constructed and used to produce the grout and avoid the large number of truckloads that would be required if grout were delivered by truck.)

This monolith will not be homogeneous in grout because it will contain encapsulated equipment that has been left in the tank (much like reinforcement steel in concrete) and residual waste. There may also be cold joints or weak plane joints. A cold joint is a discontinuity produced when the grout surface hardens before the next batch is placed against it. In the case of tank closure the cold joints would be horizontal with the ground surface. It is the intent of Hanford to control (i.e. limit) cold joint formation by maintaining as continuous a pour schedule as possible.

Figure 7-1 shows the two monolith structures produced by placement of the three layers of grout into the $15 \mathrm{ft}$ diameter swimming pools during scale-up testing. These monoliths remained after the swimming pool structures were removed. The layered monoliths displayed significant strength as demonstrated by the difficulty encountered in breaking them apart. The dozer and 
heavy-duty forklift shown in the figure were unsuccessful in turning over the monoliths. Both monoliths were repeatedly lifted on one side and dropped without breaking.

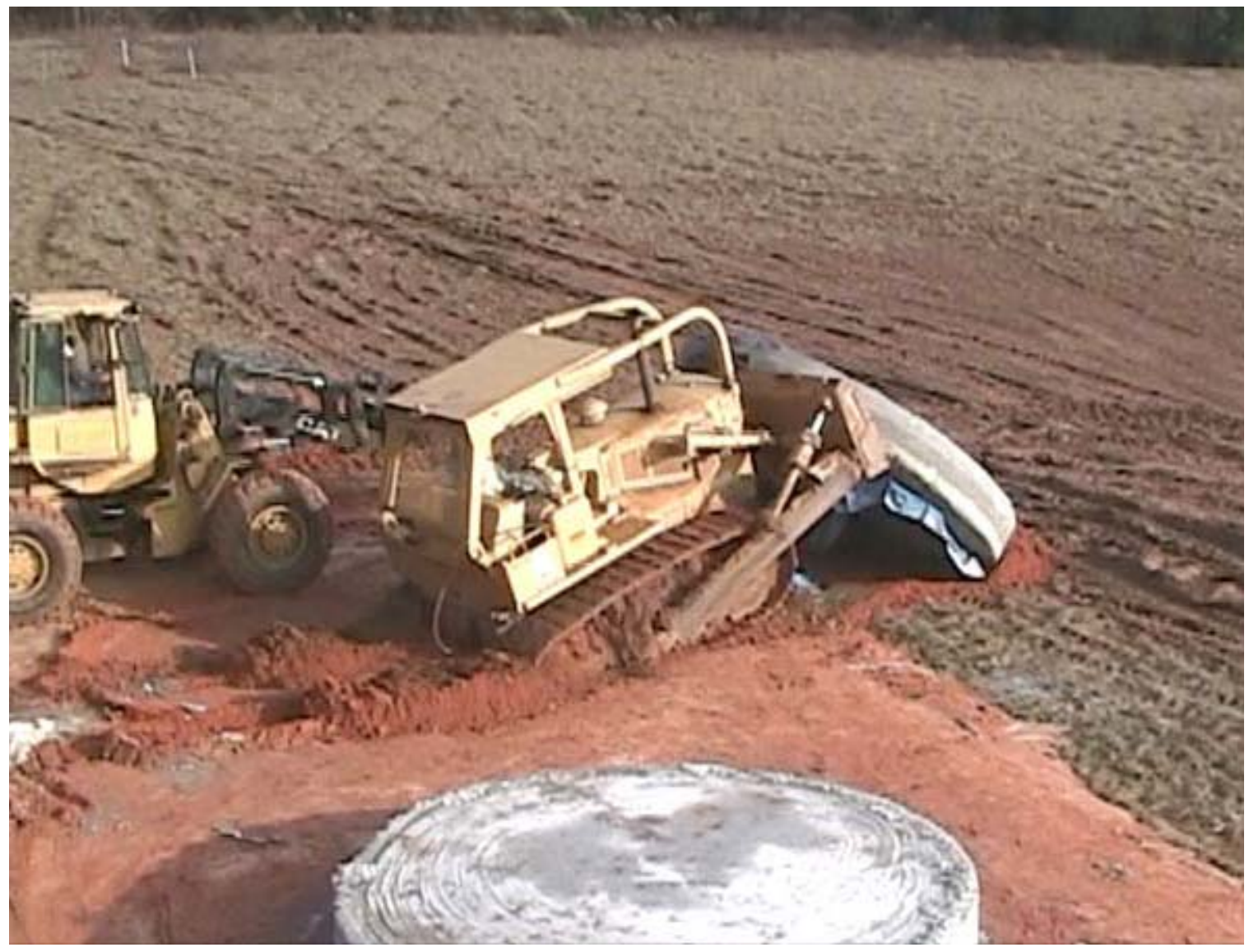

Figure 7-1 Demolition of pool 1 monolith after only 5 days after the capping layer had been poured. The monolith from pool 2 is shown in the foreground.

Eventually, the dozer was able to break the monoliths along horizontal planes by ramming the dozer blade at the level of the interfacial areas (Figure 7-.2). The horizontal fractures occurred at the location of the top dressing for pool 1 and at the interface of the stabilization grout and structural grout in pool 2. The horizontal fracture for pool 2 is shown in Figure 7-2. These structures were broken down only five days after the capping grout had been poured and a total 8 days since the pouring of the first stabilization layer. Therefore, the grouts were only in the initial phase of curing. Compressive strength measurements (see Section 9) confirmed this since significant strengthening continues to occur out to 90 days of curing. Nevertheless, this early destruction of the monolith demonstrates that a weak plane joint can be broken. 


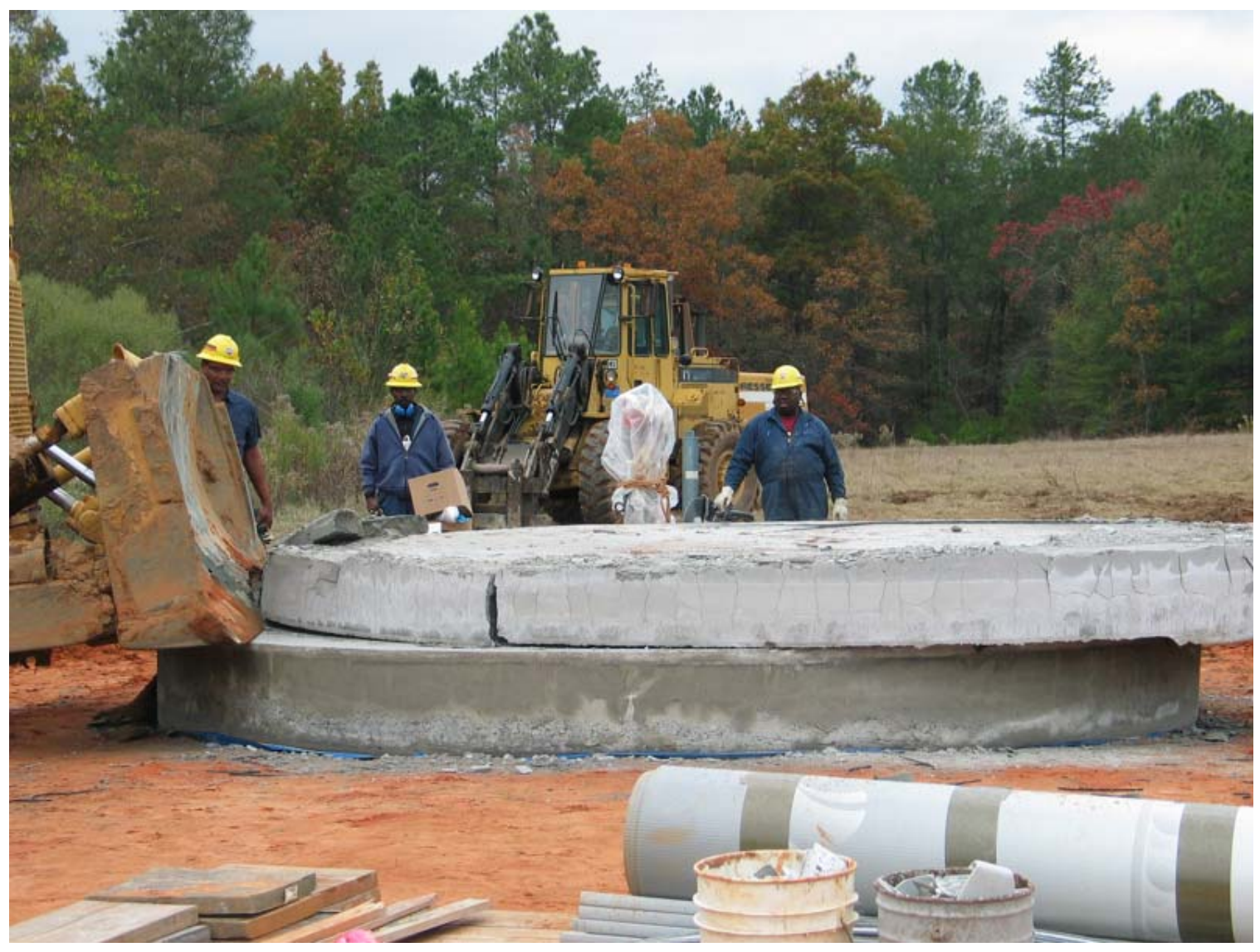

Figure 7-2 Demolition of Pool 2 monolith after only 5 days after the final capping layer was placed. Note that there is also a vertical crack in the structural and capping layer that occurred during this demolition.

\subsection{Chemical Composition}

The grout mixes developed for Hanford Single Shell Tank Closure contain sand as the main ingredient. In fact, on a mass basis, approximately $65 \%$ of the grout will be sand. This sand is composed mainly of silica and is very stable. The glue that binds the quartz sand particles together is the calcium silicate hydrate that forms as a result of hydration reactions of portland cement, blast furnace slag, and fly ash. In this sense, grout produced for single shell tank closure can be considered as manufactured sedimentary sandstone.

\subsection{Potential Degradation Processes}

Potential processes that can lead to grout degradation are (1) weathering, (2) abrasion, (3) mechanical loads, (4) freeze-thaw cycles, (5) alkali-aggregate reactions, (6) sulfate attack and delayed ettringite formation, and (7) steel corrosion induced by ingress of carbon dioxide and chloride ions. Cracking also leads to grout degradation and is discussed later in this Section. 


\subsubsection{Weathering, Abrasion and Mechanical Loads}

The grout monolith is entombed in the underground tank structure, protected from the weathering effects that exposure on the surface would bring about, and stabilized in location by the surrounding soil. Abrasion is also avoided by this underground protection. Damage due to loads on the grout is precluded by the relatively high compressive strengths of the three grout mix designs for Hanford tank closure.

\subsubsection{Freeze-Thaw Cycles}

This is not a concern for grout in tanks because temperature and moisture cycling is low for these underground tanks.

\subsubsection{Alkali-Aggregate Reactions}

The alkali-aggregate reaction occurs when aggregates containing reactive silica react with sodium and potassium oxides in the portland cement to form an alkali-silica gel. This gel can absorb water which in turn can lead to expansion and cracking of the grout. In the mixes for Hanford tank fill, non-reactive quartz ASTM C 33 sand was used. In addition, it is known that substitution of fly ash and blast furnace slag for some of the portland cement will mitigate the impact of the alkali-aggregate reactions. The design mixes for all three layers at Hanford contain both fly ash and blast furnace slag. Finally, portland cements produced today intentionally have low amounts of alkali content to avoid the alkali-aggregate reaction. Therefore, it appears unlikely that cracking due to the alkali-aggregate reaction would occur in the Hanford single shell tanks.

\subsubsection{Sulfate attack and delayed ettringite formation}

Formation of sulfate containing ettringite crystals can occur in the grout months or years after the grout has cured. This is referred to as delayed ettringite formation. The crystalline formation can lead to heterogeneous expansion in the grout or concrete and in turn produce cracking and/or spalling. This delayed ettringite formation can result from an internal source of sulfate or infiltration of sulfate into the grout from an external source.

Delayed ettringite can form from an internal sulfate source such as high sulfate cement, sulfate in the mix water supply, and/or sulfate in the aggregate. Although there may be some sulfate in the tank supernate this amount is generally small due to the extensive washing and cleaning steps that have been taken to remove the sludge. In addition, the grout is produced using low sulfate water with aggregate (fine sand) that is low in sulfate.

External introduction of sulfate is limited by the low sulfate content of the enhanced RCRA Subtitle $C$ barrier. In addition, introduction of blast furnace slag and fly ash (present in the Hanford mixes) reduce the potential for sulfate attack.

For these reasons, delayed ettringite formation and the subsequent cracking and spalling that can result, are not expected to be important as a pathway for grout degradation in the Hanford single shell tanks. 


\subsubsection{Steel Corrosion}

The steel equipment left in the tank is subject to corrosion with time due to ingress of either carbon dioxide or chloride anions. Carbon dioxide reacts with the $\mathrm{Ca}(\mathrm{OH})_{2}$ and can reduce the $\mathrm{pH}$ from the high levels normally present in the pore water. High $\mathrm{pH}$ is known to keep the encapsulated metal passivated thereby reducing corrosion rates. Chloride ions are also known to induce corrosion in steels. Therefore, the infiltration of carbon dioxide or chloride anions into the grout can lead to rusting of the steel which in turn produces expansive forces that may crack or spall the grout.

Unlike normal reinforced concrete where significant amounts of rebar are present, the single shell tanks will have relatively little equipment (and therefore steel) incorporated into the grout. It will be necessary to consider the impact of this degradation pathway separately for each tank because the amount of steel equipment left in the tanks will be tank dependent. Furthermore, chloride ions are not present in high amounts in the surrounding soil at Hanford. Both of these facts will limit this form of cracking. Nevertheless, corrosion of these materials could eventually lead to some cracking of the grout.

This same type of corrosion can occur in the steel lining of the tank. However, in this case, the steel is outside of the grout and corrosion and expansion would tend to produce a hoop stress on the grout and a outward force on the concrete walls of the tank. Calculations of the rate and extent of steel corrosion for equipment in the grout or the steel liner of the tanks were not part of the scope of this task.

\subsection{Cracking of the Grout Monolith}

Cracking within concrete and grout structures can be caused by many factors. Cracking due to the alkali aggregate reaction, corrosion of steel in the encapsulated equipment, delayed ettringite formation and freeze-thaw cycles were discussed above. Other types of cracking include plastic shrinkage, drying shrinkage, thermal cracking, and structural cracking due to loss of underlying support or an excessive load.

\subsubsection{Plastic Shrinkage}

Cracking due to plastic shrinkage occurs when evaporation of water from the surface of curing grout exceeds the replenishment of water from the mix itself. These cracks generally appear at the surface and once formed are normally dormant. In single shell tanks, under essentially continuous filling, the evaporation rate is limited and plastic shrinkage consequently avoided.

The rate of grout placement and the heats of hydration of the grouts must be managed to ensure that water evaporation from the grout surface is not significantly accelerated. High heat of hydration and rapid placement of the grout can lead to loss of water that in turn causes plastic shrinkage and crack formation at the surface of the poured grout. Measured temperature rises in adiabatically controlled conditions of the three Hanford grout mixes revealed that the highest temperature reached was $52^{\circ} \mathrm{C}\left(126^{\circ} \mathrm{F}\right)$. Calculations by ARES Corporation on the temperature profiles in the single shell tanks as a function of heat of hydration and placement rate revealed a 
maximum temperature in the tank of $55^{\circ} \mathrm{C}\left(130^{\circ} \mathrm{F}\right)$. A relatively continuous grout placement also controls the amount of water that can evaporate from the surface of the freshly poured grout.

\subsubsection{Drying}

Cracking can also be caused by drying of the grout at a time after curing is essentially complete. For this to happen in single shell tanks, water egress from the grout must be greater than water ingress into the tank and grout. These processes will be driven by the local environment including the degree of saturation of the soil and the integrity of the tank itself.

\subsubsection{Thermal Fluctuations}

Thermal cracking is caused by large variations in cured grout temperature. As previously discussed, the variations in temperature are expected to be small due to the location of the grout well below the soil surface.

\subsubsection{Structural Stress}

Structural cracking can occur due to loss of support under the tank due to soil washout or uneven compacting. This scenario is unlikely due to the fact that these tanks were placed on an engineered slab, have been in place for over 50 years, and have $\sim 10$ feet of backfill placed on top of the tanks,.

The only loads imposed on the grout will be compressive in nature and these grouts were designed to readily withstand the compressive stress of grout and soil. Therefore cracking due to a compressive load (grout and soil) is very unlikely. 


\subsection{ANCIENT CONCRETES AND MORTAR}

\subsection{Ancient Structures}

One way to gain insight into the longevity (durability) of grout, concrete and mortar is through consideration of ancient structures. Those ancient structures that utilized pozzolanic materials in conjunction with hydrated lime $\left(\mathrm{Ca}(\mathrm{OH})_{2}\right)$ best simulate modern day concrete, grout, and mortar. Some of these ancient structures have existed for over 2,000 years despite being subjected to weather, abrasion, wars and neglect. The longevity of these ancient structures, which is attributable to materials selection and placement technique, suggests that the lifetimes for the grout monoliths within the protected, underground single shell tanks at Hanford could also extend into the thousands of years.

There are many examples of ancient Roman structures that used pozzolans in the concrete and mortars used to construct the buildings, walls and floors, aqueducts, and roads. Although the following examples are not the oldest structures still standing, they are well-known and have been extensively studied. In many cases, the mortar and concrete have been sampled and analyzed for chemical composition. In other cases the samples have been subjected to carbon-14 and other dating methods.

Reviews on this subject include papers by Miller and Chapman [29] that discuss archaeological and industrial analogs for deep repository materials, Mallinson, Davies and Li [30] on historical examination of concrete in nuclear science and technology, Jull and Lees [31] on a study of historic concrete as relates to nuclear technology, and Aloy [32] that also includes ancient and old (up through the $18^{\text {th }}$ century) structures throughout Russia, Armenia, Georgia, Ukraine, and Azerbaijan.

Three examples of Roman built structures that utilize pozzolans are the Pantheon, Hadrian's Wall, and Aqueducts.

\subsubsection{Pantheon}

The Pantheon (Figure 8-1) was built approximately 19 centuries ago in Rome, and despite the elements, wars and general ravages of time, it is still standing and functional today. 


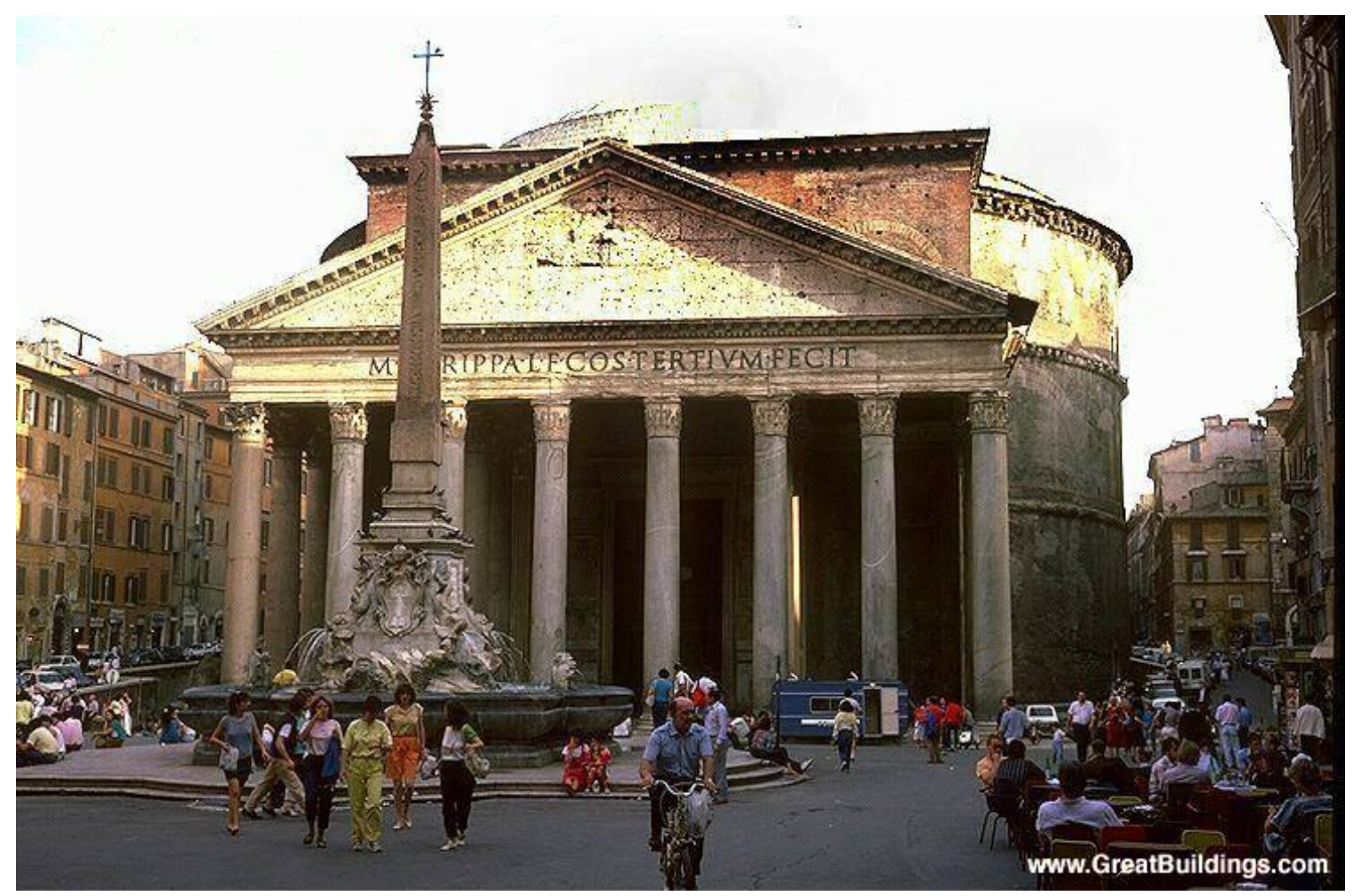

Figure 8-1 Pantheon

This building was built in its entirety without any steel reinforcing rods. For the concrete dome to last this long without reinforcing rods is a remarkable achievement. Interestingly, the dome and walls have developed several cracks which are thought to have occurred shortly after construction. However, these cracks have not interfered with the functional utilization of the building.

\subsubsection{Hadrian's Wall}

Hadrian's Wall (Figure 8-2) was also built by the Romans to separate modern day Scotland from the rest of Britain. It is an example of the durability of mortar that was used to bind the stones together that comprised the wall, the forts, and the buildings that were all part of the 84 mile barrier. 


\section{HADRIAN'S WALL}

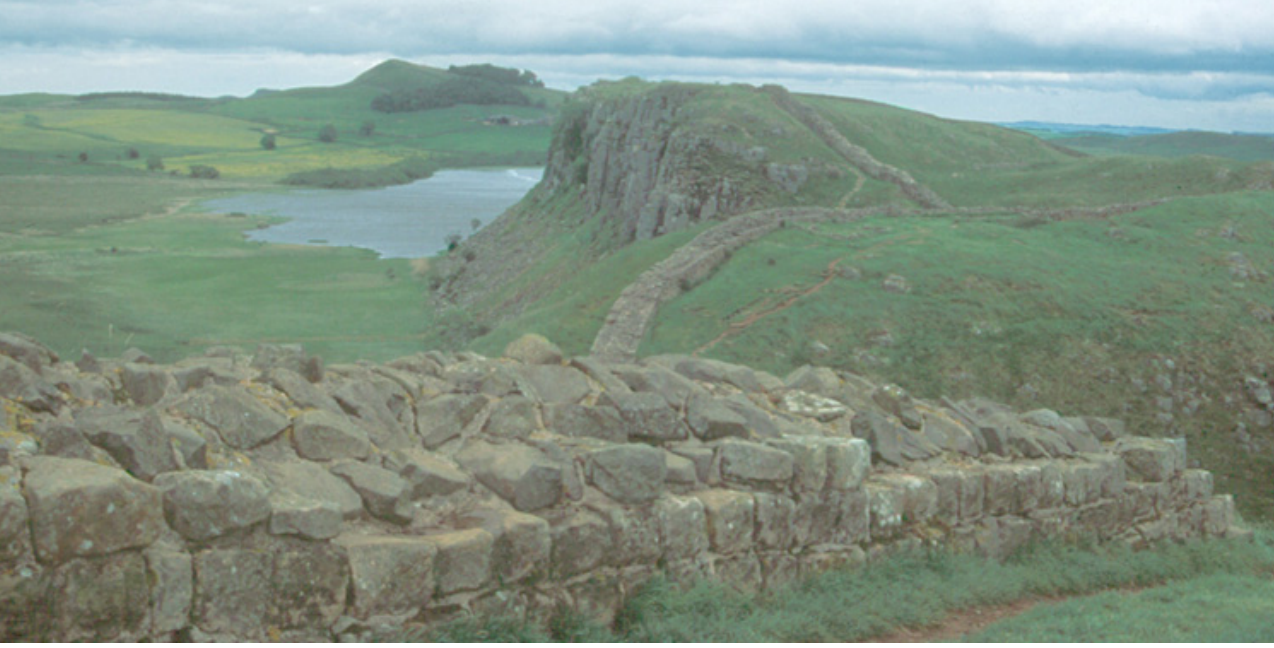

Figure 8-2 Hadrian’s Wall

\subsubsection{Roman Aqueducts}

The Roman Aqueduct system (Figure 8-3) was used to transport well water to the major cities in ancient Rome.

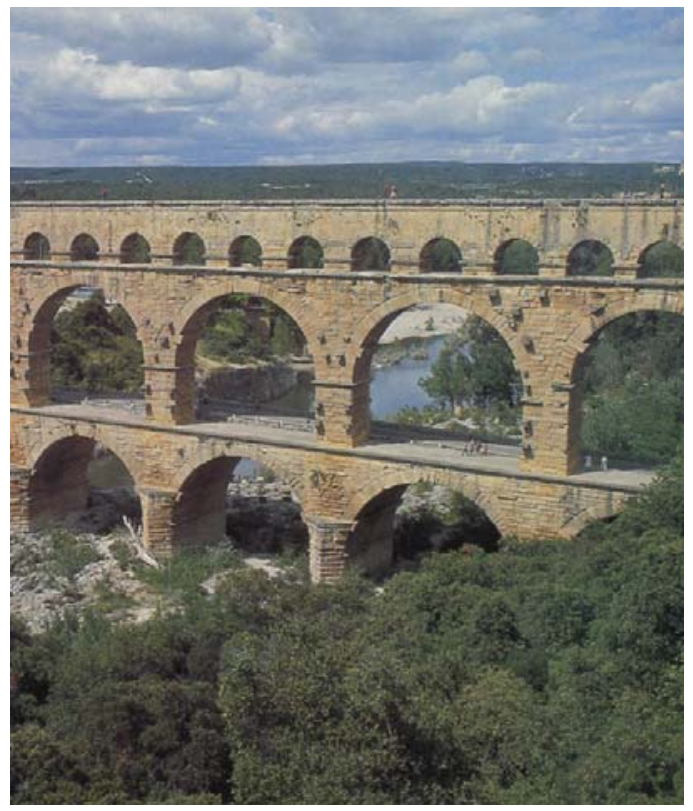

Figure 8-3 Roman Aqueducts 
The materials of construction included concrete, stone, brick and mortar. The concrete and mortar used in these systems had to be designed to resist infiltration of water through use of pozzolans (volcanic ash) in the mix. These aqueducts had both underground and above ground sections as part of the delivery system to the cities.

\subsection{Chemistry of Ancient Cements and Mortars}

The use of lime or hydrated lime alone in ancient cements and mortars produced a hardened structure through carbon dioxide infiltration and reaction with the slaked lime. In the absence of any hydraulic additives, the normal formation of calcium silicate hydrates was precluded in the early mortars and concretes. It turns out that the Romans used volcanic ash from the town of Pozzuoli in Italy as an additive to the early concretes and mortars. This glassy material reacts with calcium hydroxide and undergoes the normal hydraulic reactions that lead to calcium silicate hydrates, the glue that binds the sand particles or other aggregates together. (The origin of the word pozzolan comes from the discovery of this material in Pozzuoli, Italy and is used generally today to refer to materials that when activated, undergo hydraulic reactions.) The resultant material is stable in water much like modern day concrete.

The above examples cited in this Section all had pozzolans added to the fresh mixture to produce these more durable, water stable structures. Therefore, despite the fact that portland cement was not invented until the early 1800's, the basic chemistry leading to the durability of these ancient concretes and mortars, is the same as that of modern day concretes. In the mixes developed for Hanford, the class F fly ash and the blast furnace slag can both be considered as pozzolans that are activated by the calcium hydroxide. These mixes also contain portland cement so that all three binders generate calcium silicate hydrates during reactions with water. 


\subsection{HANFORD GROUT DESIGN MIXES AND PROPERTIES}

This section details the design mixes for the Hanford stabilization, structural, and capping grout layers, operational flexibility within the ranges specified, and the measured fresh and cured properties of these mixes.

\subsection{Hanford Design Mixes}

The design mixes were developed at the bench scale for the Hanford stabilization, structural, and capping grouts. These design mixes used portland cement, fly ash and a fine sand available in Washington State. Holcim blast furnace slag was used in the formulation development because the only available source of slag was from Holcim in Birmingham, Alabama. The final formulations for these three mixes are provided in Table 9-1. The amount of water present in each of these formulations was based on an ASTM C6103 flow of 15 inches.

Table 9-1 Design mixes for the stabilization, structural, and capping grouts for Hanford.

\begin{tabular}{|l|c|c|c|c|}
\hline Ingredients & Supplier & $\begin{array}{c}\text { Stabilizing } \\
\text { HRG4 }\end{array}$ & $\begin{array}{c}\text { Structural } \\
\text { HRG2 }\end{array}$ & $\begin{array}{c}\text { Capping } \\
\text { HRG9 }\end{array}$ \\
\hline Portland cement $\left(\mathrm{lbs} / \mathrm{yd}^{3}\right)$ & Ash Grove, WA & 225 & 75 & 280 \\
\hline Slag $\left(\mathrm{lbs} / \mathrm{yd}^{3}\right)$ & Holcim, AL & 210 & 210 & 210 \\
\hline Fly ash $\left(\mathrm{lbs} / \mathrm{yd}^{3}\right)$ & Central Pre-Mix, WA & 225 & 375 & 170 \\
\hline Sand $\left(\mathrm{lbs} / \mathrm{yd}^{3}\right)$ & Central Pre-Mix, WA & 2530 & 2530 & 2530 \\
\hline Water $\left(\mathrm{gal} / \mathrm{yd}^{3}\right)$ & SRS Domestic & 58 & 54 & 62 \\
\hline Kelco-Crete ${ }^{\circledR}\left(\mathrm{g} / \mathrm{yd}^{3}\right)$ & CP Kelco, CA & 275 & 275 & 275 \\
\hline ADVA $^{\circledR}$ Flow $\left(\mathrm{fl.oz} / \mathrm{yd}^{3}\right)$ & W. R. Grace & 90 & 90 & 90 \\
\hline
\end{tabular}

Two options were provided for the dry grout mixture. The first contained equal quantities of portland cement, blast furnace slag, and fly ash while the second option allows for the replacement of fly ash with sand (C-33 or C-404)

\subsection{Scale-up Testing and Equivalency}

For the scale-up testing performed at SRS, materials available locally within the South Carolina/Georgia area were used. This was to done to reduce the impact on schedule and budget of transporting materials from Washington. An equivalency formulation was developed for each of the three mixes using materials available locally at SRS. The final formulations for these three mixes are provided in Table 9-2. The amount of water present in these formulations was based on an ASTM C6103 flow of 15 inches. 
Table 9-2 Design mixes for the stabilization, structural, and capping grouts for Hanford Tank Closure using SRS locally available materials.

\begin{tabular}{|l|c|c|c|c|}
\hline Ingredients & Supplier & $\begin{array}{c}\text { Stabilizing } \\
\text { SRG4 }\end{array}$ & $\begin{array}{c}\text { Structural } \\
\text { SRG2 }\end{array}$ & $\begin{array}{c}\text { Capping } \\
\text { SRG9 }\end{array}$ \\
\hline Portland cement $\left(\mathrm{lbs} / \mathrm{yd}^{3}\right)$ & Giant Cement, SC & 225 & 75 & 280 \\
\hline Slag $\left(\mathrm{lbs} / \mathrm{yd}^{3}\right)$ & Holcim, AL & 210 & 210 & 210 \\
\hline Fly ash $\left(\mathrm{lbs} / \mathrm{yd}^{3}\right)$ & $\begin{array}{c}\text { Southeastern Fly Ash, } \\
\text { NC }\end{array}$ & 225 & 375 & 170 \\
\hline Sand $\left(\mathrm{lbs} / \mathrm{yd}^{3}\right)$ & LaFarge, GA & 2150 & 2150 & 2150 \\
\hline Water $\left(\mathrm{gal}^{\mathrm{yd}} \mathrm{yd}^{3}\right)$ & SRS Domestic & 66 & 58 & 66 \\
\hline Kelco-Crete $^{\circledR}\left(\mathrm{g} / \mathrm{yd}^{3}\right)$ & CP Kelco, CA & 275 & 275 & 275 \\
\hline ADVA $^{\circledR}{\text { Flow }\left(\mathrm{fl} . \mathrm{oz} / \mathrm{yd}^{3}\right)}^{\text {W. }}$ & W. Rrace & 90 & 90 & 90 \\
\hline
\end{tabular}

Additional bench scale work was performed with the SRS equivalent mixes that expanded the range of admixture concentration from 1.0 to 1.5 times the values given in Tables 9-1 and 9-2. This admixture range provided flexibility during scale-up testing and was used in the development of the grout specifications. This testing also provided insight into the changes in the properties of the grouts from the bench scale to scale-up level. Although some changes were noted from bench to scale-up, compliance with the requirements was still achieved.

The range of admixture concentrations from 1.0 to 1.5 times the design mix amounts was not investigated for the design mixes using Hanford Area materials. Therefore, additional bench scale testing with this admixture range for Hanford Area materials by the grout placement contractor is recommended. It is further recommended that this range of admixture concentrations with Hanford Area materials be tested at production scale using the production equipment prior to tank filling (see Recommendations).

\subsection{Water Content of Sand}

The water content in the mix plays a significant role in the flow and development of bleed water of the grout mix. The available water comes from the water added to the mix plus any water that is sorbed on the grains of sand. The water content of the sand varies with the method of storage, with location, and with the local meteorological conditions. Consequently, the amount of water in the sand can vary not only day to day but within the day as well. An example of the dependence of the amount of water that must be added in gallons per cubic yard for the Hanford structural grout design mix (HRG2) as a function of the sorbed water content on the sand is provided in Figure 9-1. This variability is important to take into account and is discussed further in the next section. 
Gallons of Water Added to Hanford Structural Grout Mix

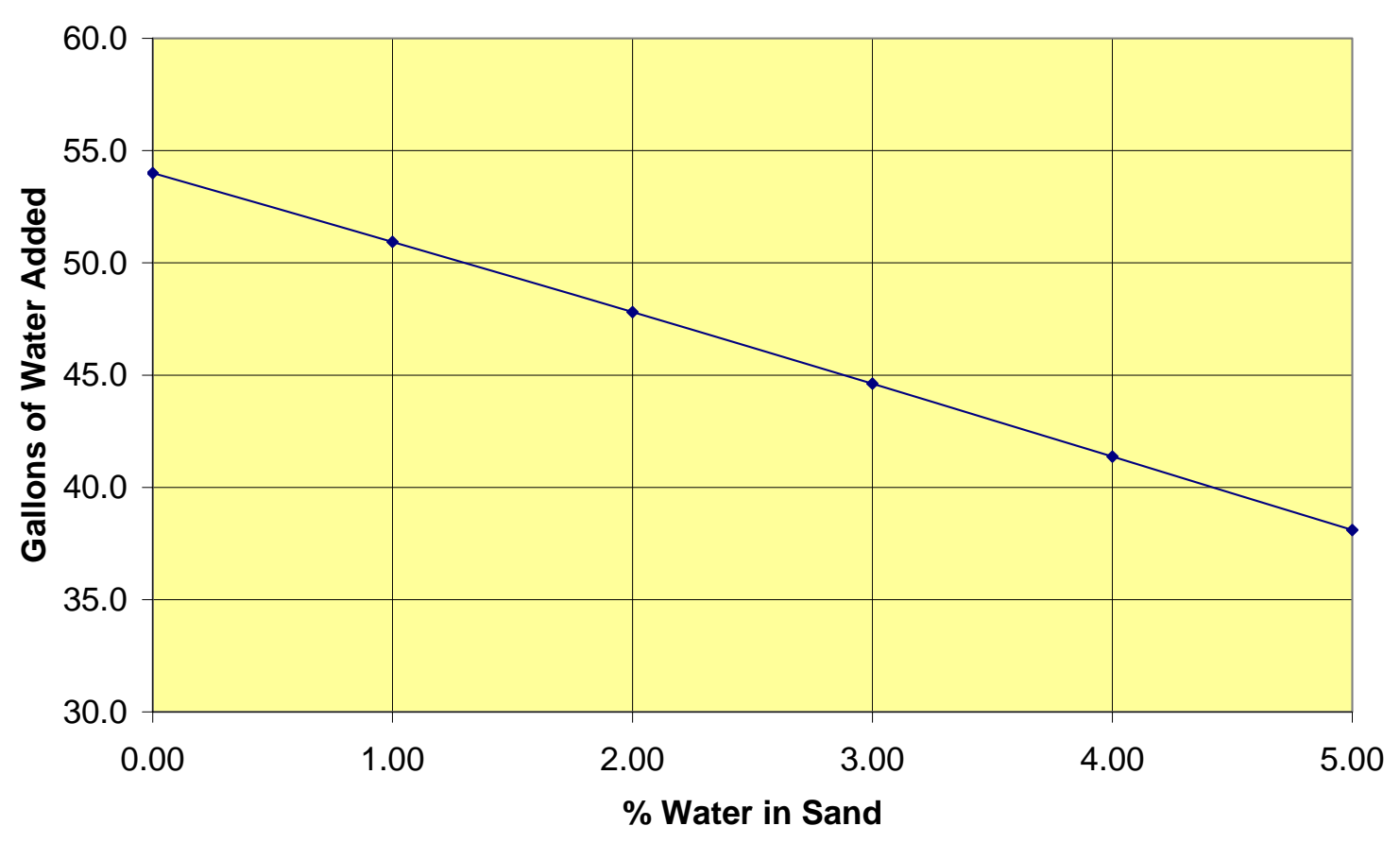

Figure 9-1 The number of gallons of water to be added per cubic yard of grout as a function of the percentage of water in the sand.

\subsection{Operational Flexibility}

Day-to-day variability in the fresh properties of grout mixes is normal (e.g., as a consequence of the change in the water content of the sand as described above). Therefore, it is important to provide flexibility in the design mix (grout) specification in order that an operator can adjust the mix as required to obtain the desired outcome.

This flexibility is provided to the operator by allowing a range of grout flow by ASTM C6103 (12 to 15 inches) through a range in the concentrations of admixture (1.0 to 1.5 times the nominal value) and water in the mix. The key objectives for a grout design mix in terms of placement are (1) a grout flow which allows for completely filling the tank and (2) the absence of bleed water. These two objectives need to be balanced by appropriate selection of the concentrations of water and admixture.

The grout specifications provide additional details on this operator flexibility and responsibility to monitor filling and adjust water content and admixture concentration as necessary. 


\subsection{Grout Properties}

This section provides the fresh and cured grout properties measured during the course of this investigation.

\subsubsection{Fresh Grout Properties}

Flow. The flow, as measured by ASTM D6103 was measured for all mixes at the bench and pilot scales. Flow between 12 inches and 15 inches is an acceptable value as long as there is no bleed water. The grout specifications provide a range of admixtures and a maximum amount of water for these mixes. The admixture and water content of the mixes can be adjusted by the operator prior to placement in the tanks to achieve the required flow with no bleed water.

Bleed Water. In the bench scale studies, no bleed water was observed with the design mixes (ASTM C 232). Again, the operator has flexibility as detailed in the grout specifications, to adjust both the admixture concentration (within a fixed range) and the water concentration (not to exceed maximum values) in order to obtain a mix with no bleed water.

During scale-up testing at the Savannah River Site, several of the adjusted mixes exhibited bleed water after 24 hours even though the mixes had flow measurements that were within the acceptable range of 12 to 15 inches as determined by ASTM C6103. The bleed water for these mixes ranged from 0.6 to $1.4 \mathrm{vol}$. \% as detailed in the scale-up report [3]. The mixes that exhibited bleed water contained an admixture concentration at the low end of the range. On the other hand, none of the mixes that had a concentration of admixture at the upper end of the range exhibited bleed water.

As recommended above, bench-scale and production-scale testing should be performed on a series of mixes using Hanford Area materials prior to filling the tanks by the operator. This data will assist the operator in making adjustments of the design mixes during production thereby producing a grout with acceptable flow and no bleed water.

Flow and Placement Rate. The Hanford design for tank filling is based on a $90 \mathrm{cyd} / \mathrm{hr}$ grout placement rate through a center riser for C-106. The flow of grout to the tank edge and the filling of the tank without voids is a function of the placement rate and strategy as well as the grout formulation for the grout. The scale-up testing at SRS and the fact that the Hanford mixes have similar flowability to the SRS tank fill mixes (which have been demonstrated to completely fill tanks $17 \mathrm{~F}$ and $20 \mathrm{~F}$ ), support the conclusion that tank filling with grout can lead to a completely filled tank without voids. For comparison, the maximum placement rate achieved at the Savannah River Site during closure of Tanks 17 and 20 was 80 cyd/hr. Tanks 17F and 20F have a diameter of 80 feet.

The original intent of the scale-up testing was to determine the feasibility of placement of the grout through a near edge riser which would consequently require a flow of up to 80 feet. Therefore, grout flow was tested using 80-feet long trenches (Figure 9-2). Four pours were made into the ends of these trenches directly from the cement truck. These tests successfully demonstrated flow of all three grout mixes over the length of the trench to produce a relatively 
level surface. However, this was accomplished only when using high placement rates ( 340 to $500 \mathrm{cyd} / \mathrm{hr}$ ).

Two additional pours were made in the trenches through a slick line attached to the pump truck at placement rates of $\sim 70 \mathrm{cyd} / \mathrm{hr}$. A flow of 75 feet was achieved for the first placement at this rate from the end of the trench but the grout was not self-leveling. For the second pour through a slick line, the placement was made near the center of the trench onto the sloped layer of grout resulting from the first pour. The second grout placement resulted in enhanced flow along the down-slope. This last result suggests that grout placement made onto a previously placed, sloped layer will have a gravity-accelerated flow rate relative to a flow along a level surface.

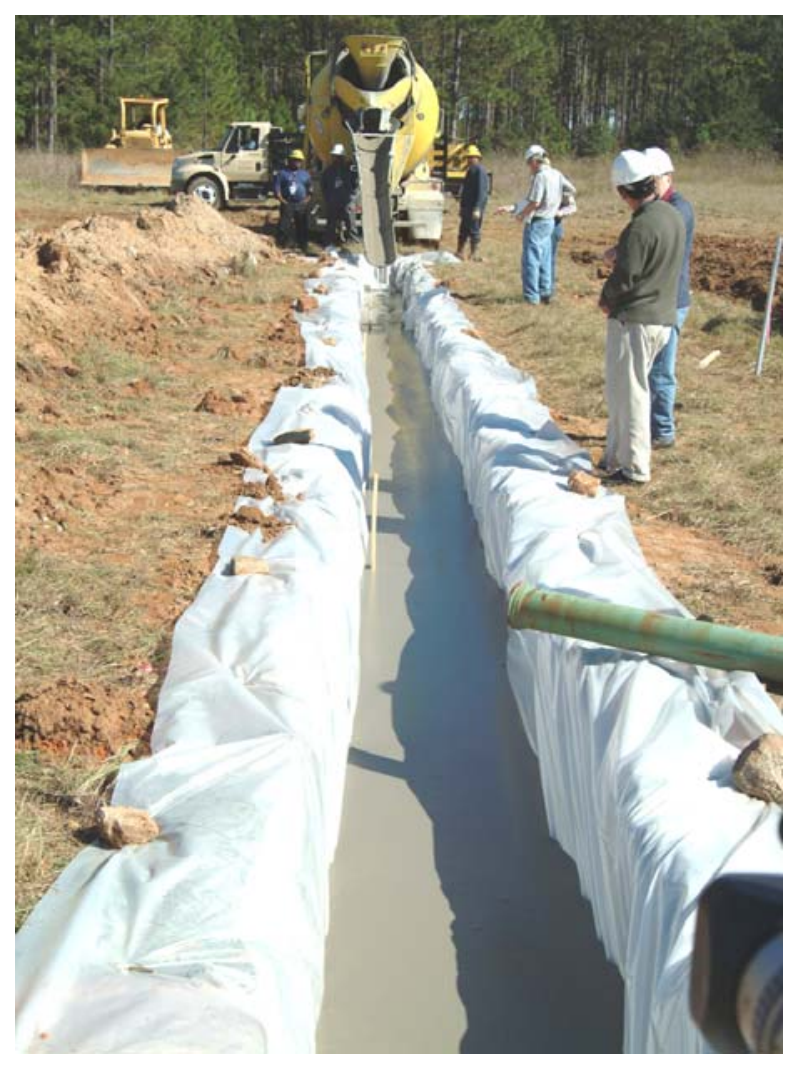

Figure 9-2 Photograph taken immediately after placement of the stabilization grout into the 80 $\mathrm{ft}$. long trench.

Submerged Grout Placement. The purpose of these tests was to determine whether grout can be placed from a submerged location in fresh grout against a head of up to 8 feet. Two separate placements were made into culverts that were 10 feet tall and 2 feet in diameter. The placements were made at a level 2 feet above the bottom of the culverts (Figure 9-3).

The first placement used the capping grout mix and resulted in excessive bleed water after placement. Therefore, a second placement was performed using a new capping grout mix that contained 1.5 times the admixture and less water than the mix used in the first placement. The 
second mix with a flow of 11 inches was readily placed in this configuration with no evidence of bleed water.

These results reveal that at higher admixture and lower water content, a capping grout can be placed through a head of up to 8 feet. This corresponds to placement of the capping grout into the dome region of a tank through a riser. Further experimentation would be required to determine the optimal amounts of water and admixture with the Hanford materials for this type of placement.

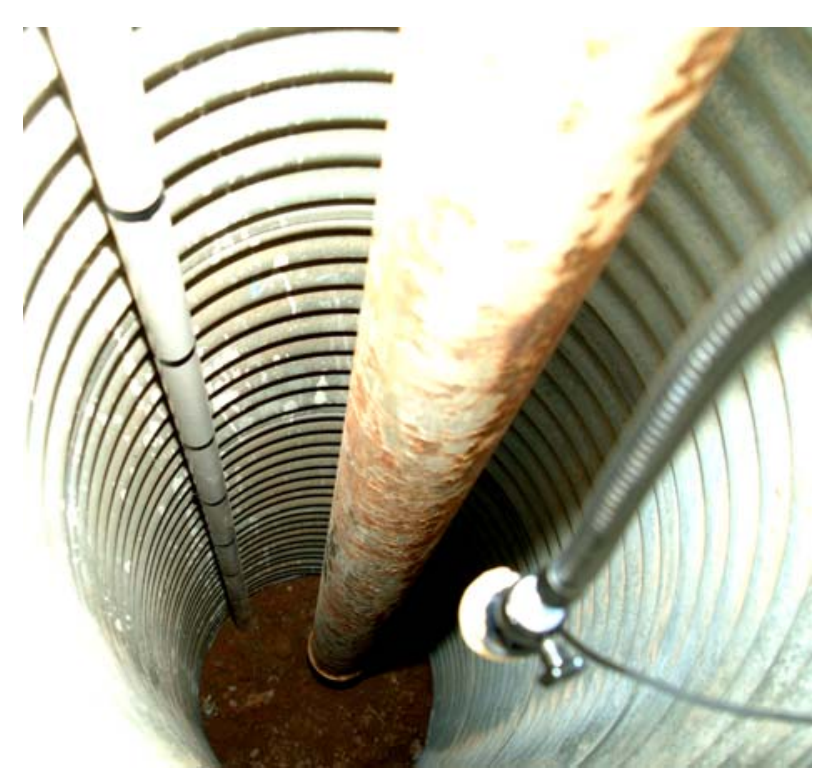

Figure 9-3 Metal culvert looking down from the top.

Grout Placement from Ten Feet. A test was performed in which the grout mix was dropped from a height of ten feet to determine whether segregation (separation of the water as bleed water) of the mix would occur. This test was performed using a capping grout and resulted in bleed water in the trench. However, samples taken from the truck and examined the next day revealed that this mix of SRG9 had bleed water. Therefore, segregation may have resulted from the mix itself or through the action of dropping 10 feet.

Therefore, given the information that is available at this stage, it is important to avoid placement from large distances ( $\sim 10 \mathrm{ft}$ ) and/or to use a Tremie for placement. On the other hand, the grouts poured during the cascade line testing (Section 10) demonstrate no problem with placement from $\sim 5$ feet.

Grout Placement through a Tremie. Grout placement through a Tremie was successfully demonstrated using a capping grout mix (see Figure 9-4). The goal of the testing was to demonstrate the feasibility of using a Tremie for placement in Hanford single shell tanks. This type of placement allows for the Tremie to be introduced into the tank through the riser and 
positioned a certain distance from the bottom of the tank or grout level (e.g., two feet above the level of tank bottom or recently poured grout). This type of placement can preclude free-fall dropping of grout over larger distances. As previously discussed, grout placement from distances of 10 feet or greater may lead to segregation.

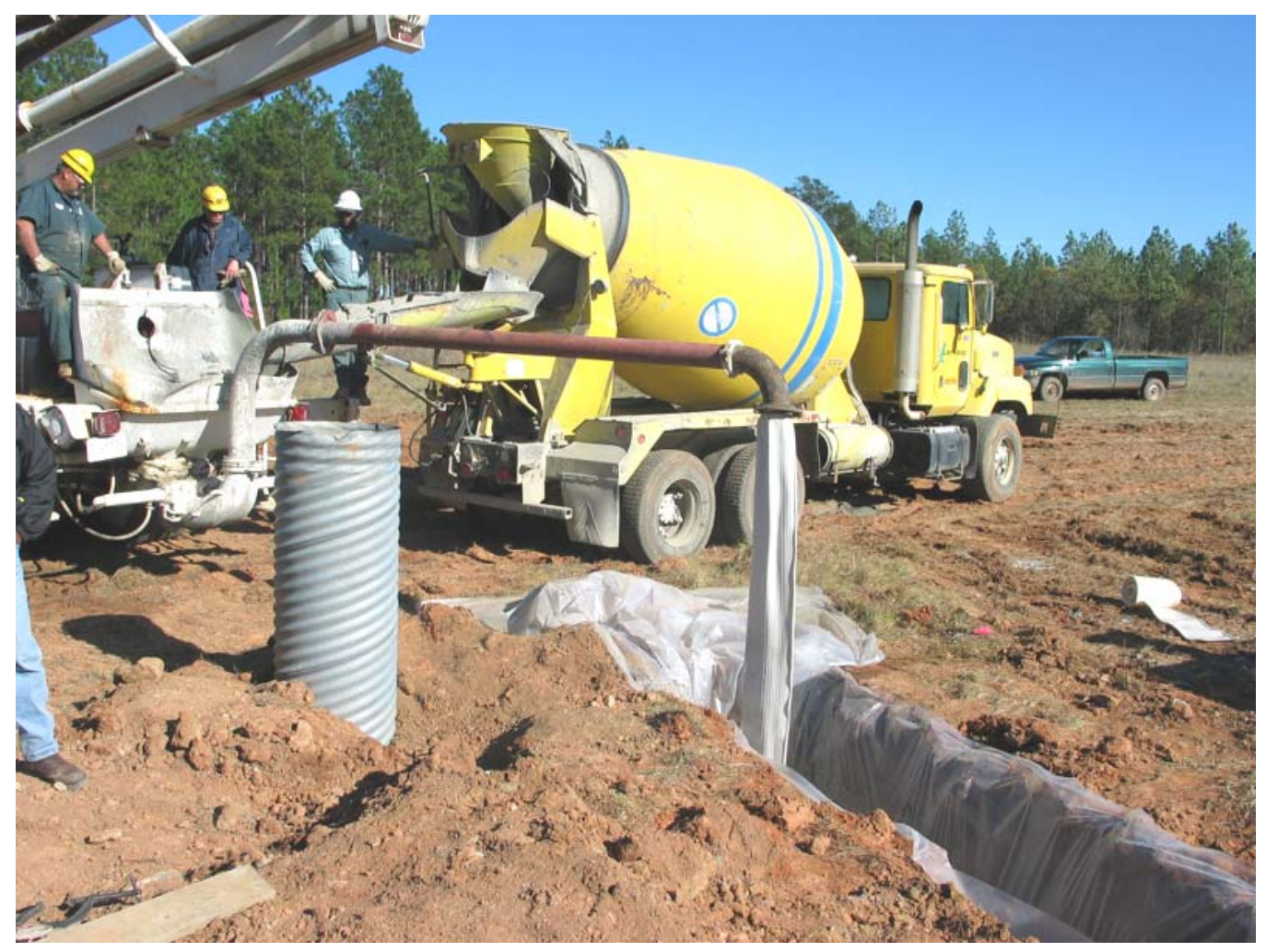

Figure 9-4 Placement of grout into a trench through a Tremie. Note the metal culvert in the foreground which was used for the submerged grout placement test.

Effect of Vibration of Grout. A test was performed to determine whether a concrete vibrator would enhance flow without leading to segregation. The grout was placed in the trench through a slick line. There was an immediate appearance of bleed water when the concrete vibrator was turned on and the amount of bleed water generated was significant. Therefore, it appears that grout mixes will undergo segregation when subjected to vibration. 


\subsubsection{Cured Grout Properties}

Compressive Strengths (psi). The compressive strengths for the design mixes are presented below. Because the grout specifications provide a range of water and admixture concentrations, these values will vary slightly over the ranges of admixture and water concentrations.

\begin{tabular}{|c|c|c|c|}
\hline Property & $\begin{array}{c}\text { Stabilization } \\
\text { HRG4 }\end{array}$ & $\begin{array}{c}\text { Structural } \\
\text { HRG2 }\end{array}$ & $\begin{array}{c}\text { Capping } \\
\text { HRG9 }\end{array}$ \\
\hline $\begin{array}{c}\text { Compressive Strength } \\
(14 \text { days) in psi }\end{array}$ & 630 & 535 & 740 \\
\hline $\begin{array}{c}\text { Compressive Strength } \\
(28 \text { days) in psi }\end{array}$ & 1620 & 825 & 3885 \\
\hline $\begin{array}{c}\text { Compressive Strength } \\
(90 \text { days) in psi }\end{array}$ & 3465 & 1275 & \\
\hline
\end{tabular}

Unit Weight (lbs/ft $\mathbf{f t}^{3}$. The unit weight of grout is the grout density and is expressed in lbs/ $\mathrm{ft}^{3}$. The values for the three design mixes are as follows:

\begin{tabular}{|c|c|c|c|}
\hline Property & $\begin{array}{c}\text { Stabilization } \\
\text { HRG4 }\end{array}$ & $\begin{array}{c}\text { Structural } \\
\text { HRG2 }\end{array}$ & $\begin{array}{c}\text { Capping } \\
\text { HRG9 }\end{array}$ \\
\hline Unit Weight $\left(\mathrm{lbs} / \mathrm{ft}^{3}\right)$ & 135.3 & 132.1 & 136.5 \\
\hline
\end{tabular}

Set Time (hours). The set times for these three grouts are:

\begin{tabular}{|c|c|c|c|}
\hline Property & $\begin{array}{c}\text { Stabilization } \\
\text { HRG4 }\end{array}$ & $\begin{array}{c}\text { Structural } \\
\text { HRG2 }\end{array}$ & $\begin{array}{c}\text { Capping } \\
\text { HRG9 }\end{array}$ \\
\hline Set Time (hours) & $<24$ hours & $<24$ hours & $<24$ hours \\
\hline
\end{tabular}

Adiabatic Temperature Rise $\left({ }^{\mathbf{0}} \mathbf{C}\right)$. The qualitative adiabatic temperature rise over approximately 12 days was measured for the three design mixes and the results are shown below.

\begin{tabular}{|c|c|c|c|}
\hline Property & $\begin{array}{c}\text { Stabilization } \\
\text { HRG4 }\end{array}$ & $\begin{array}{c}\text { Structural } \\
\text { HRG2 }\end{array}$ & $\begin{array}{c}\text { Capping } \\
\text { HRG9 }\end{array}$ \\
\hline $\begin{array}{c}\text { Approximate Temperature } \\
\text { Rise ( } \sim 12 \text { Days })\end{array}$ & $\sim 29^{\circ} \mathrm{C}$ & $\sim 14{ }^{\circ} \mathrm{C}$ & $\sim 27^{\circ} \mathrm{C}$ \\
\hline
\end{tabular}

Effective Diffusion Coefficient ( $\left.\mathbf{c m}^{2} / \mathbf{s e c}\right)$. The effective diffusion coefficients and leach indices were determined for grout samples. Samples were prepared with binder ingredients and tested according to an abbreviated ANSI/ANS 16.1 protocol [25]. Because the effective 
diffusion coefficients and leach indices are derived from the measurements of Tc-99 in the solutions, the uncertainties of these measured quantities lead to uncertainties for the resulting coefficients and indices. The sensitivity of the coefficients and indices to measurement uncertainty is presented in the table below. In this table, effective diffusion coefficients and leach indices are determined for three Tc-99 leach values: the nominal Tc-99 measurement, the measurement +2 sigma, and the measurement -2 sigma, where sigma represents the standard deviation of the random variation of the analytical process as reported by Sandia National Laboratory. Thus, with approximately $95 \%$ confidence, the effective diffusion coefficient ranged from $4.0 \mathrm{E}-12$ to $6.17 \mathrm{E}-10 \mathrm{~cm}^{2} / \mathrm{sec}$ and the leach index ranged from 10.0 to 13.7 .

\begin{tabular}{|c|c|c|c|}
\hline Property & Measured Value & $\begin{array}{c}\text { Measured Plus } \\
\text { 2 Sigma }\end{array}$ & $\begin{array}{c}\text { Measured Minus 2 } \\
\text { Sigma }\end{array}$ \\
\hline $\begin{array}{c}\text { Effective Diffusion } \\
\text { Coefficient }\left(\mathrm{cm}^{2} / \mathrm{sec}\right)\end{array}$ & $1.39 \mathrm{E}-10$ & $6.17 \mathrm{E}-10$ & $4.0 \mathrm{E}-12$ \\
\hline Leach Index & 11.0 & 10.0 & 13.7 \\
\hline
\end{tabular}

Saturated Hydraulic Conductivity ( $\mathbf{c m} / \mathbf{s e c})$. The saturated hydraulic conductivity was not a required measurement but is provided for potential use in modeling water infiltration.

\begin{tabular}{|c|c|c|c|}
\hline Property & Stabilization & Structural & Capping \\
& HRG4 & HRG2 & HRG9 \\
\hline Hydraulic Conductivity & $5.9 \mathrm{E}-08$ & $2.5 \mathrm{E}-07$ & $3.8 \mathrm{E}-08$ \\
\hline
\end{tabular}

Young's Modulus (psi). The measurement of the stiffness of the grout was measured by determining Young's Modulus. These values are:

\begin{tabular}{|c|c|c|c|}
\hline Property & Stabilization & Structural & Capping \\
& HRG4 & HRG2 & HRG9 \\
\hline Young's Modulus (psi) & $3.3 \mathrm{E}+05$ & $2.3 \mathrm{E}+05$ & $3.6 \mathrm{E}+05$ \\
\hline
\end{tabular}

Shrinkage (\%). Although shrinkage was not a design requirement of the grout, this measurement was made on both HRG4 and HRG2 cured samples during the bench scale formulation development work. The results are:

\begin{tabular}{|c|c|c|}
\hline Property & Stabilization (HRG4) & Structural (HRG2) \\
\hline Decrease in Length (\%) & 0.008 & 0.003 \\
\hline
\end{tabular}


Air Content (\%). Air content was measured (ASTM C 231) on both HRG4 and HRG2 cured samples during the bench scale formulation development work. The results are:

\begin{tabular}{|c|c|c|}
\hline Property & Stabilization (HRG4) & Structural (HRG2) \\
\hline Air Content (\%) & 4.0 & 6.5 \\
\hline
\end{tabular}

\subsection{Equipment Filling with Cable Grouts}

Proof-of-principle experiments were designed and performed to demonstrate the feasibility of filling equipment left in place in the Hanford single shell tanks. The testing demonstrated that a vertical 1-inch pipe 20 feet long can be easily filled either by gravity pouring from the top or by pumping the grout through a tube inserted to within a few inches of the bottom of the pipe. Dissection of pipes indicated that filling was complete and that even small obstructions (electrical wires) were completely encapsulated in grout (Figure 9-5).

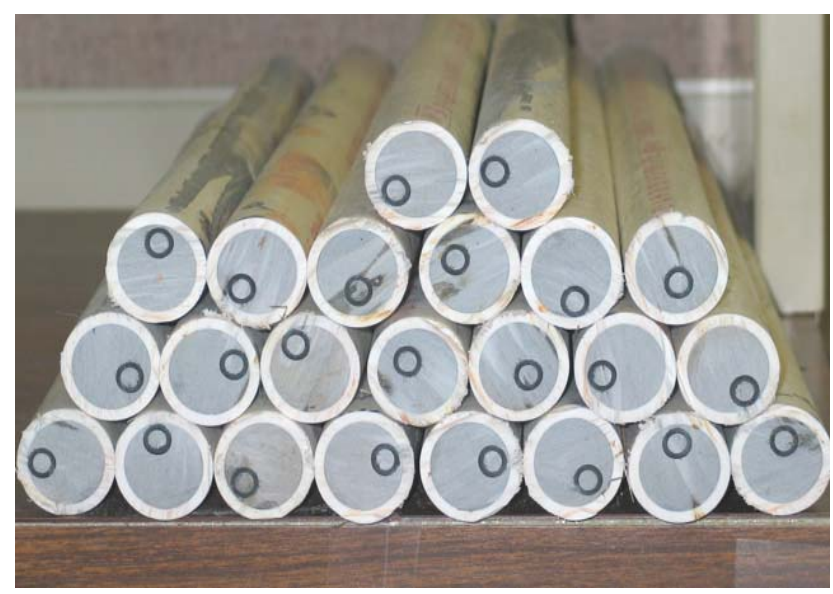

Figure 9-5 One-inch PVC pipe filled with Masterflow 1205 grout.

Filling the 1-inch diameter PVC pipes with cable grouts demonstrated that commercially available grouts can be used for stabilizing equipment left in the tanks by filling the internal void spaces as long as access from the tank top is available. The selection of a particular cable grout will depend on the field conditions for the equipment that requires filling. Details of the three cable grouts tested are included in the scale-up report [3] 


\subsection{CASCADE LINES}

\subsection{Introduction to Cascade Lines}

The Hanford Single Shell High-Level Waste Tanks are interconnected by carbon steel pipes in a cascade arrangement near the top of the carbon steel liner. These carbon steel connecting pipes are referred to as cascade lines. The presence of cascade lines raises the possibility of grout entering the cascade line during placement of the grout and flowing into a neighboring tank. The single tank being closed must either be isolated from the other tanks prior to grout placement or it must be demonstrated that grout placement will lead to isolation of the tank through selfsealing of the lines with grout. Scale-up testing was performed to address the latter option and demonstrated, through a proof of principle test, the feasibility of self-sealing the cascade lines during normal placement of the grout into the tanks.

The cascade lines are 3-inch, schedule 80 carbon steel pipes that extend 1 foot into the single shell tank. The nominal value for the length of a cascade line is 27 feet while the nominal value for the cascade line slope is 3.125\% corresponding to an angle of 1.8 degrees with respect to horizontal. The location of the cascade line connection to the tank is at a height in the tanks where Phase 2 Structural Grout will be placed.

Grout placed into a tank at the nominal maximum rate of 90 cyd/hr produces on average an increase in the height of the grout in the tank of 0.11 inch every minute. Therefore, once the grout reaches the bottom of the cascade line, it will take an additional 27 minutes of continuous placement at $90 \mathrm{cyd} / \mathrm{hr}$ to reach the top of the cascade line.

\subsection{Experimental Setup}

The experimental set up is shown in Figure 10-1. Basically, the single shell tank was simulated by a $16 \mathrm{ft}$ diameter swimming pool that was roughly $5 \mathrm{ft}$ high. This pool was placed on a level, engineered concrete pad. Cascade lines were simulated using a transparent polycarbonate pipe that had a 3-inch internal diameter. These lines were connected to the pool at an angle of 2 degrees from horizontal such that the exit end of the cascade line was lower than the end that was connected to the pool. The line extended into the interior of the pool a length of one foot to simulate the actual tank configuration. 


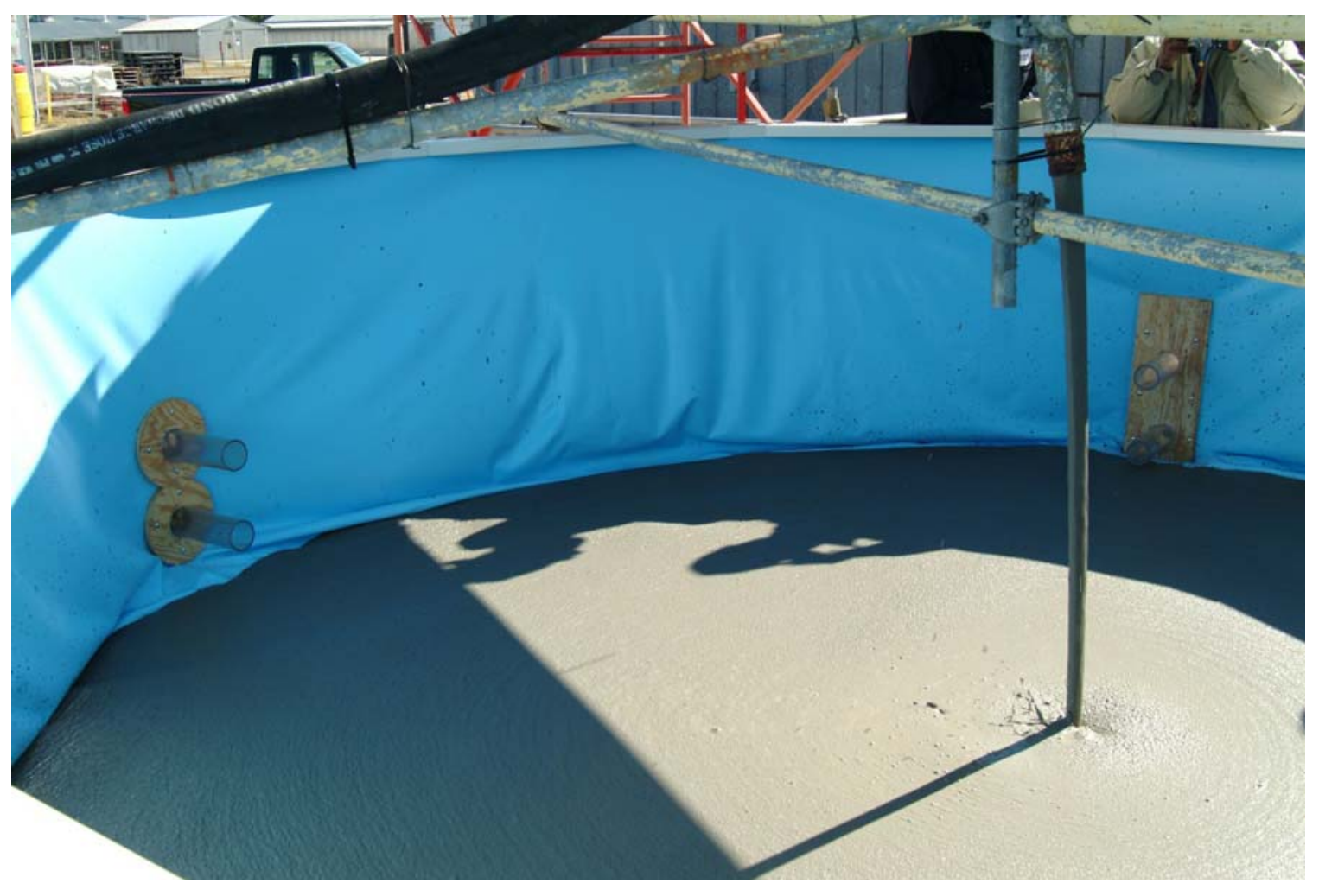

Figure 10-1 Experimental setup showing the four cascade lines. This photograph was taken during placement of the first truckload of grout into the pool.

Placement rate of grout into the pool was controlled by a variable speed Putzmeister TK-25 grout pump (Figure 10-2). The grout was pumped through a flexible slick line to the center of the pool and discharged directly downward into the pool (see Figure 10-1). The TK-25 can vary the placement rate between 0 and $24 \mathrm{cyd} / \mathrm{hr}$. 


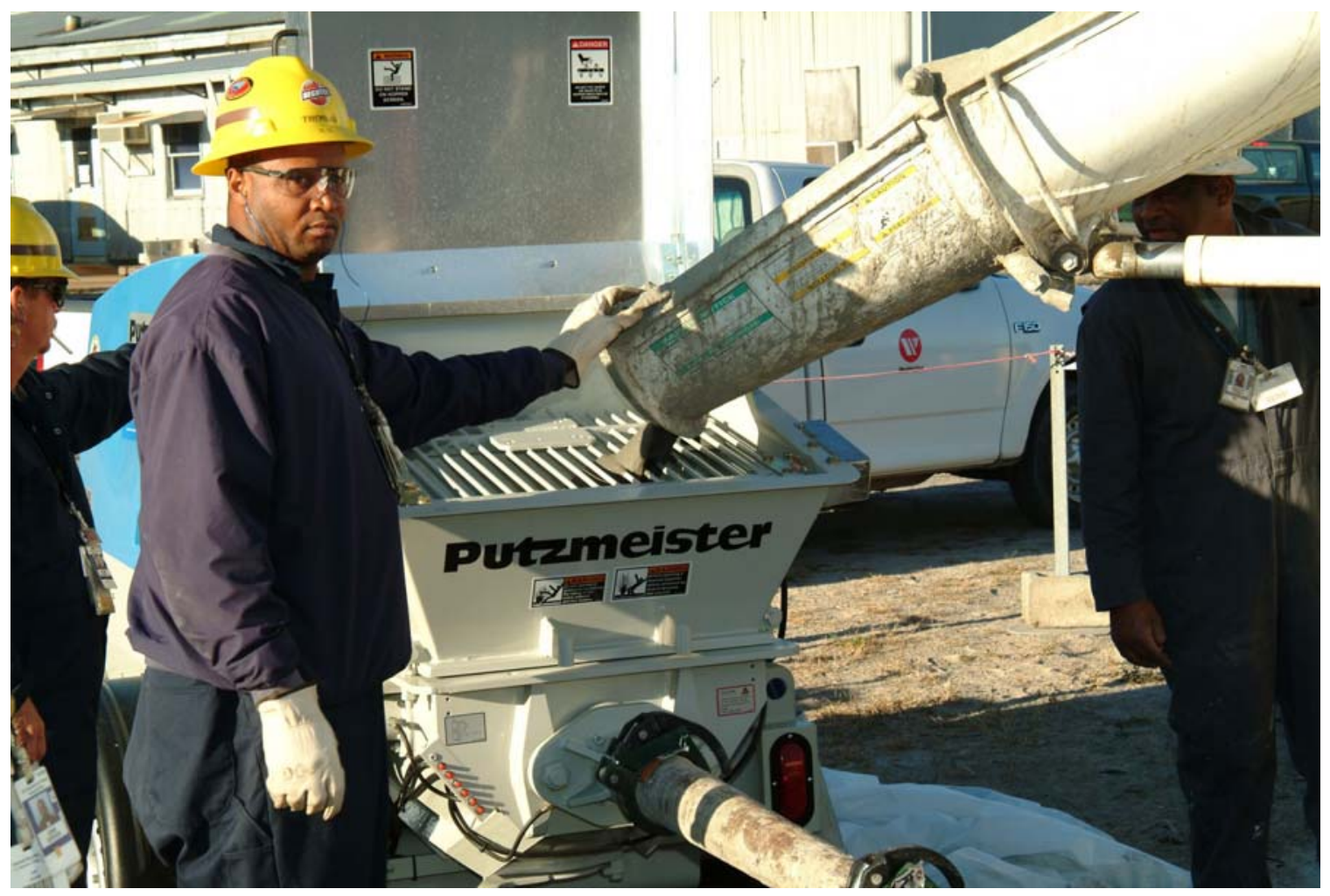

Figure 10-2 The grout was fed from the Ready Mix truck to the Putzmeister pump hopper and subsequently pumped at a controlled rate to the pool.

The experimental details for the two tests that were performed are provided in Table 10-1. Additional details of the testing are provided in the final report for cascade line testing [5]. 
Table 10-1 Approximate values of relevant parameters for the two tests

\begin{tabular}{|l|c|c|}
\hline & TEST 1 & TEST 2 \\
\hline Design Mix & Structural, SRG2 & Structural, SRG2 \\
\hline Flow & 13 inches & 14 inches \\
\hline Diameter of Swimming Pool & 16 feet & 16 feet \\
\hline Volume of Placement & 8 cyd & 9 cyd \\
\hline Height of Placement in Pool & 1 foot & 1 foot \\
\hline Location of Placement & Center & Center \\
\hline Rate of Placement & 23 cyd/hr & 23 and 12 cyd/h* \\
\hline Length of Time for Placement & 20 minutes & 25 minutes \\
\hline $\begin{array}{l}\text { Change in Height with Time } \\
\text { Reference Tank Case - 90 } \\
\text { cyd/hr }\end{array}$ & 0.56 inches/minute & $\begin{array}{l}0.56 \text { and } 0.30^{*} \\
\text { inches/minute }\end{array}$ \\
\hline $\begin{array}{l}\text { Ratio of Change in Height with } \\
\text { Time to Reference Tank case }\end{array}$ & 0.11 inches/minute & 0.11 inches/minute \\
\hline Ambient Temperature & 5.1 (0.56/0.11) & 5.1 and 2.7* \\
\hline Mix Temperature & 64 degrees F & 69 degrees F \\
\hline Number of Cascade Lines & 2 & 68 degrees F \\
\hline
\end{tabular}

*The $23 \mathrm{cyd} / \mathrm{hr}$ placement rate at 0.56 inches/minute and a ratio of 5.1 was used for the lower cascade line and the $12 \mathrm{cyd} / \mathrm{hr}$ placement rate at 0.30 inches/minute and a ratio of 2.7 was used for the upper cascade line of Test 2.

\subsection{Results of the Cascade Line Testing}

Two proof-of-principle large-scale tests simulated the flow of grout into Hanford single-shell single shell tanks and into cascade lines which interconnect the single shell tanks. The goal of the testing was to determine whether the single shell tank grout can enter the cascade line and solidify prior to flowing into an adjacent tank.

The tests were conducted using the Phase 2 Structural Grout, SRG2. This is the grout that will be placed in the tank at the location of the cascade line openings.

The first test used a mix that had lower water content than the mix used in the Test 2. A flow (flow consistency) of 13 inches was measured using ASTM D-6103. This grout, although it did travel a distance of 4.5 feet down the lower cascade line under the head pressure of an additional 6 inches of grout, stopped flowing when the lift was completed (Figure 10.3). No further movement of the grout down the cascade line occurred during the second lift, added approximately 4 hours later. The top cascade line in this testing had very little grout in the line since it did not have the immediate head pressure during the first lift nor was it forced into the line during the second placement of grout. 


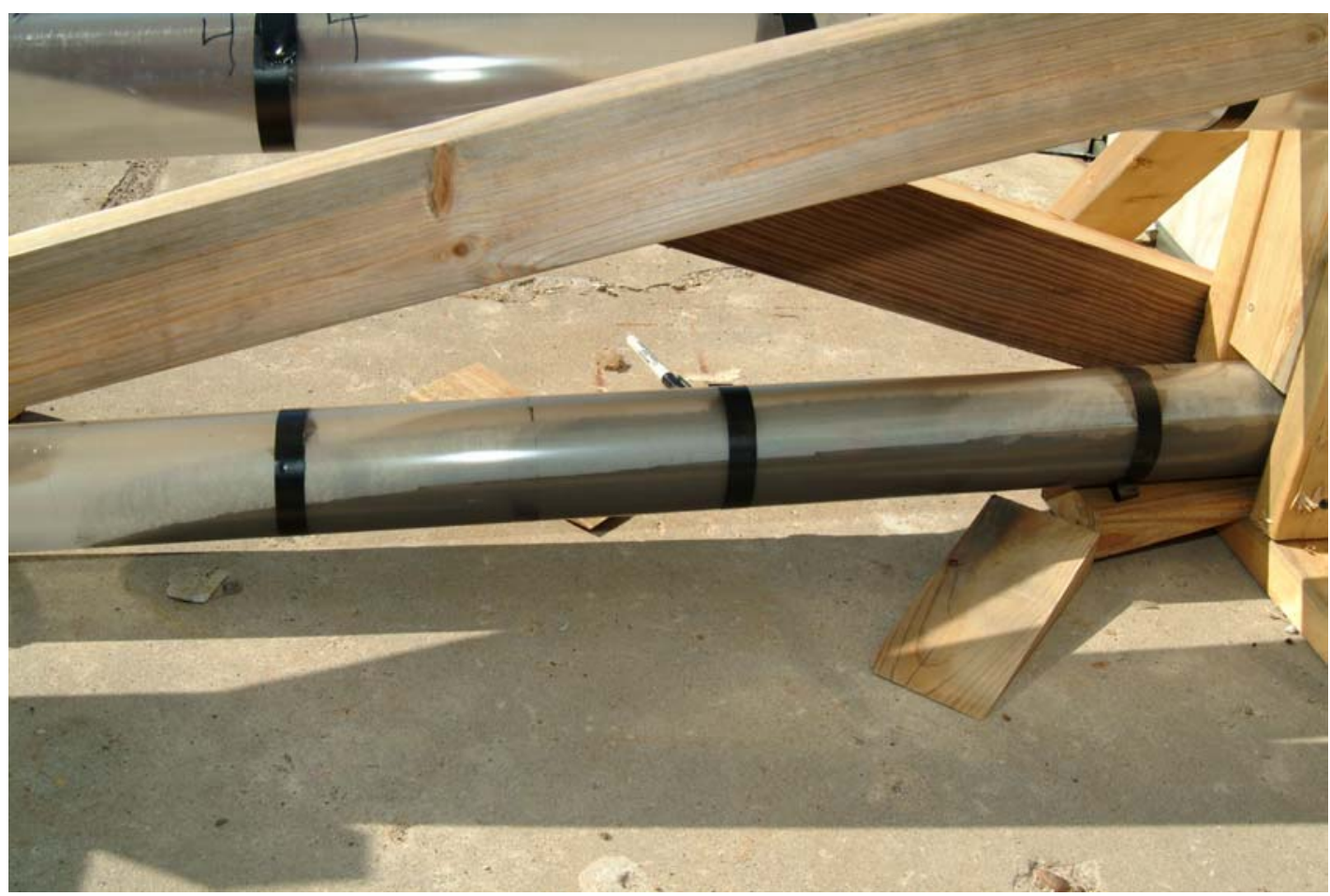

Figure 10-3 The grout flowed approximately 4.5 feet down the cascade line (see the $4 \mathrm{ft}$ mark on top cascade line).

The second test used the same SRG2 Structural Grout but with a higher concentration of water than used in the first test. This higher water mix resulted in a grout with a flow greater than 14 inches as measured using ASTM D-6103. This grout was very fluid during placement and readily flowed down the two cascade lines used for Test 2 . The cascade lines, which were 16 feet long, were entirely filled with grout. In this case, the grout flowed down the cascade lines even without the head pressure of additional grout.

The Hanford Grout Specifications provide specifications and guidance on mix designs for tank closure. For a given mix design and range of admixture concentrations, a flow of between 12 inches and 15 inches by ASTM D-6103 will produce a grout with acceptable compressive strength and no bleed water. However, the guidance directs the operator to increase water in the mix (but still be within the 12 to 15 inch ASTM D-6103 flow) if the grout flow in the tank is not sufficient to readily reach the edge of the tank.

\subsection{Discussion of the Cascade Line Testing}

These two tests provided two different outcomes for this task. In Test \#1, self-sealing of the cascade lines was demonstrated by grout with at flow of $\sim 13$ inches. For Test \#2, the lines did not self seal and the grout (flow of $\sim 14$ inches) readily traveled the entire 16 feet (actual cascade lines are $\sim 27 \mathrm{ft}$ ) and flowed out the end of the lines. 
The only difference between these two tests was the amount of water added to the mix. The difference in water content was 4 gallons per cubic yard of grout (55 gallons/cyd in Test \#1 and 59 gallons/cyd in Test \#2. The mix used in Test \#2 was clearly more fluid and more selfleveling than the mix used in Test \#1.

During normal placement activities, a mix similar to that used in Test \# 2 is preferred due to high fluidity. However, at or near a cascade line, a mix similar to that used in Test \#1 is preferred due to the fact that self-sealing of the cascade lines was observed. The tradeoff in using a stiffer mix as in Test \#1 is a reduction in flowability and self-leveling property of the grout.

\subsection{Conclusions for the Cascade Line Testing}

This cascade line testing provided a proof-of-principle demonstration that self-sealing of the cascade lines is achievable during grout placement in single shell tanks for a grout mix design with an ASTM D-6103 flow of 13 inches. However, if the operator increases the water content of the mix to increase flowability in the tank and in the process increased the ASTM D-6103 flow to 14 inches (still within the range of the specification), then the grout could flow through the cascade lines.

Therefore, it is likely that there is a level of water content between the two tested levels that leads to a higher confidence in simultaneously achieving good flow and self-leveling properties while also achieving self-sealing of the cascade line. 


\subsection{SAVANNAH RIVER SITE APPROACH TO TANK CLOSURE}

Two tanks at Savannah River Site’s F-Tank Farm were closed in 1997 [6,7]. These tanks (17F and 20F) both of which have 1.3 million gallon capacity were cleaned to the extent practical and then, completely filled with grout. A temporary grout plant was installed to produce and place the grout into the tanks. The next two tanks to be closed at SRS are Tanks 19F and 18F in FTank Farm.

The tanks at SRS are regulated under an Industrial Wastewater Permit issued by the State of South Carolina. The details of the closure plans for these tanks can be found in the overall Closure Plan [33] and in the individual Closure Modules for tanks 17F and 20F [34,35].

\subsection{Waste Removal}

Three jet mixer pumps (slurry or centrifugal pumps) were used in each tank to dissolve salt and suspend the sludge particles. For Tank 20F, the material was removed from the tank with a steam eductor while for Tank 17F, the waste was removed with a centrifugal pump. Final cleaning of both tanks was accomplished using spray washing.

For Tank 20F, an estimated 1000 gallons of residual waste was left in the tank after cleaning. This corresponds to $~ 1 / 4$ inch layer if the waste was distributed evenly on the bottom of this 85 feet diameter tank. For Tank 17F, the estimated amount of residual waste was 2,200 gallons.

\subsection{Grout Materials}

Three separate grout layers were placed during filling of these two tanks. The first layer used reducing grout, the intermediate, bulk fill layer used controlled low-strength material (CLSM), and the top layer, the strong grout layer, used a higher compressive strength CLSM. Figure 11-1 provides a representation of these three layers in a SRS tank [36]. 


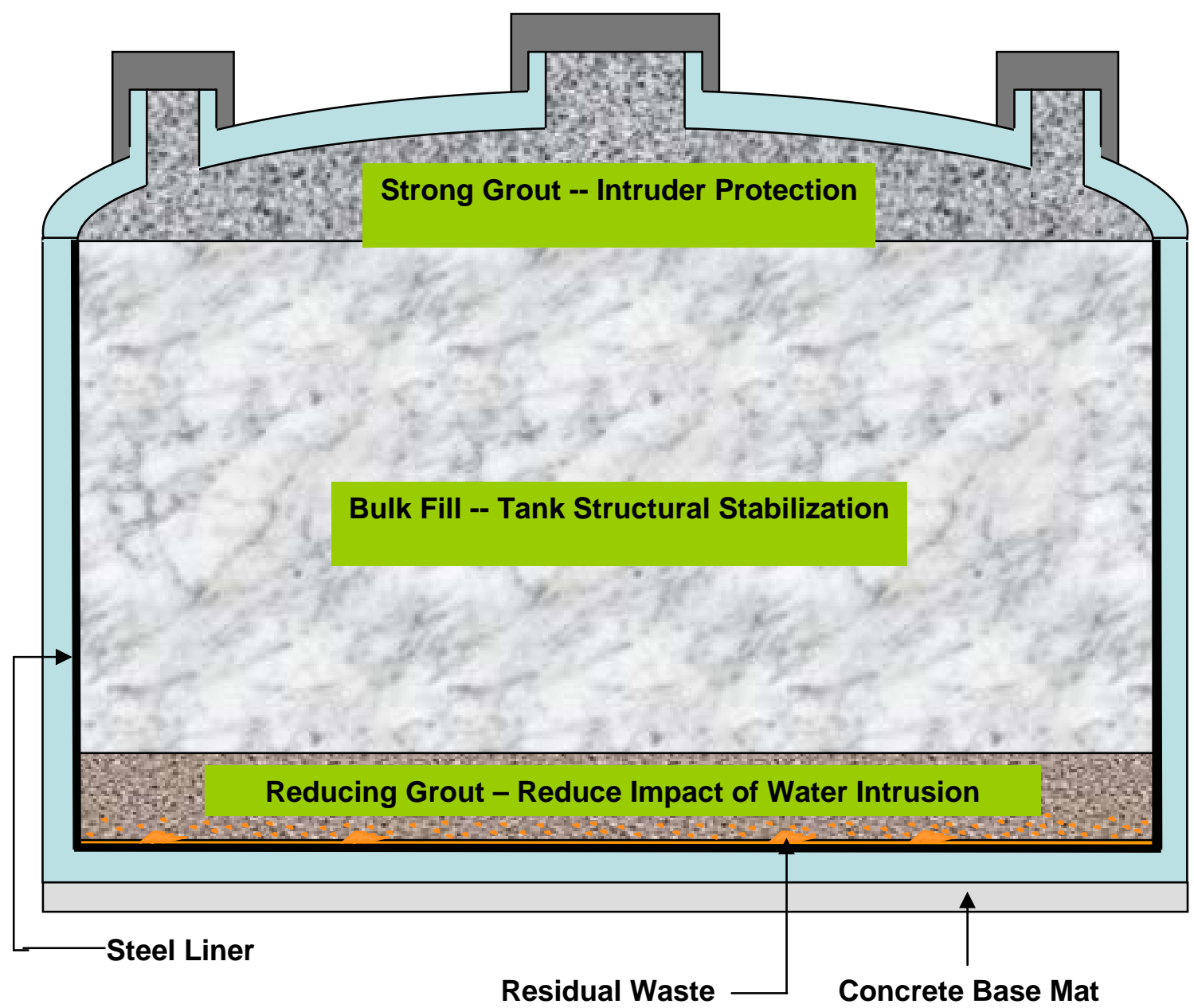

Figure 11-1 Representation of a tank after placement of the three layers of grout at SRS.

\subsubsection{Reducing Grout}

The reducing grout was developed by Construction Technology Laboratories, Inc., CTL, of Skokie, Illinois. This mixture is equivalent in concept to the stabilization layer for Hanford. The design mix contained Type $\mathrm{V}$ portland cement, ground granulated blast furnace slag, fine sand, silica fume, sodium thiosulfate, and several admixtures (a high-range water reducer and a set retarder).

This mix contained two different reducing agents, one introduced with the slag and the other from the added sodium thiosulfate. The purpose of this reducing capacity is to reduce the $\mathrm{Tc}(\mathrm{VII})$ pertechnetate to the Tc(IV) insoluble phase.

After the first pass of reducing grout, dry grout powder was introduced into the tank to solidify the supernate. After the last placement of dry grout, another layer of reducing grout was added. This ensured that the dry grout layer, which contains the radionuclides originally present in the supernate, was sandwiched between two layers with reductive capacity. 


\subsubsection{Bulk Fill, Controlled Low Strength Material (CLSM) Layer}

The bulk fill, CLSM layer is equivalent to the Structural layer for Hanford Tank Closure. The primary goal here is to prevent tank subsidence. SRNL developed a CLSM grout for SRS tank closure that contained portland cement, fine sand, and Class F fly ash. After curing, this material has a consistency similar to hard packed soil. A superplasticizer and thickener were added to this mix to prevent bleed water while still obtaining acceptable flow. This mixture did not contain blast furnace slag in contrast to the design mix for Hanford where the structural grout contains blast furnace slag. The inclusion of slag in the Hanford mix provides additional reductive capacity as part of a conservative approach to prevent the re-oxidation of Tc(IV) to pertechnetate.

\subsubsection{Strong Grout, Water Layer}

The strong grout layer was also a CLSM material that was similar to the previous layer, but with a higher content of portland cement. The increased cement loading provided a compressive strength that was $>2,000$ psi. This $>2,000$ psi requirement is intended to reduce the possibility of an inadvertent intrusion in the future (e.g., by drilling a well). This layer contained no blast furnace slag in contrast to the Hanford capping layer which does contain blast furnace slag. The inclusion of slag in the Hanford mix provides additional reductive capacity as part of a conservative approach to prevent the re-oxidation of Tc(IV) to pertechnetate.

\subsubsection{Specifications for Savannah River Mix Designs}

The specifications for the grout formulations used to close Tanks $17 \mathrm{~F}$ and $20 \mathrm{~F}$ are provided in the Table 11-1. See Reference 37 for details of all mix designs. 
Table 11-1 Mix designs for the Savannah River Site closure of Tanks 17F and 20F.

\begin{tabular}{|c|c|c|c|}
\hline Ingredients & $\begin{array}{c}\text { Reducing } \\
\text { Grout }\end{array}$ & $\begin{array}{l}\text { Bulk Fill } \\
\text { (CLSM) }\end{array}$ & Strong Grout \\
\hline Portland cement (lbs/yd ${ }^{3}$ ) & 1353 (Type V) & 150 (Type I/II) & 550(Type I/II) \\
\hline Slag (lbs/yd $\left.{ }^{3}\right)$ & 209 & - & - \\
\hline Fly ash $\left(\mathrm{lbs} / \mathrm{yd}^{3}\right)$ & - & 500 & - \\
\hline Sand (lbs/yd ${ }^{3}$ ) & 1625 & 2300 & 2285 \\
\hline Water (gal/ $\left.\mathrm{yd}^{3}\right)$ & 86.4 & 63 & 60 \\
\hline Silica Fume (lbs/yd $\left.{ }^{3}\right)$ & 90 & - & - \\
\hline HRWR (fl.oz/yd ${ }^{3}$ ) & 250 & 90 & 140 \\
\hline Viscosity Modifier (fl.oz/yd ${ }^{3}$ ) & - & 275 & 275 \\
\hline Set Retarder (fl.oz/yd ${ }^{3}$ ) & 75 & - & - \\
\hline
\end{tabular}

\subsection{Grout Production and Placement}

A temporary, mobile grout plant was installed in F Tank Farm and operated by a subcontractor, G. L. Throop Company of Pasadena. The plant was located 1000 feet from the tanks.

Therefore, the grout had to be pumped through a slick line by a piston-type positive displacement pump to the tops of the tanks. The grout plant had two continuous feed volumetric mixers that delivered grout to the pump. Each mixer could produce $30 \mathrm{cyd} / \mathrm{hr}$. Typically the plant would operate for 10 hrs/day, five days a week.

\subsection{Lessons Learned}

Several lessons were learned during these tank closures and they are summarized in the Innovative Technology Summary Report [7]. Several important lessons learned are:

- New grout formulations, particularly for the reducing grout layer are required to reduce complexity, cost, and the high heat of hydration of the mix.

- A careful analysis is required to determine the type of ventilation systems required based on need.

- Placement through a center riser as the main pathway for filling tanks is the preferred option. 
WSRC-TR-2005-00195

Revision 0

This page intentionally left blank. 


\subsection{RECOMMENDATIONS}

This Section summarizes the recommendations made throughout this Report. This testing is part of startup testing by the grout placement contractor to adjust for his equipment, the actual materials and environmental factors at Hanford.

- Bench scale testing over the extended admixture range (1.0 to 1.5 times the amounts specified in design mixes for Hanford) for Hanford Area materials by the grout placement contractor is recommended. It is further recommended that this range of admixture concentrations with Hanford Area materials subsequently be tested at production scale using the production equipment prior to tank filling.

- Depending on the need for self-sealing of the cascade lines, additional testing with the Hanford materials is recommended to identify a grout composition within the range tested by SRNL that will satisfy the conditions of self-sealing and flow within the tank.

- Depending on the need for submerged grout placement, additional testing with the Hanford materials is recommended to identify a grout composition that will satisfy the conditions of submerged grout placement.

- Testing of cable grouts to fill equipment left in the tank demonstrated the feasibility of these grouts in general. However, it is recommended that the need for and the performance of additional testing be carried out as necessary depending on the actual equipment that will need to be filled. 


\subsection{CONCLUSIONS}

This report is a summary of the bench-scale and large scale experimental studies performed by Savannah River National Laboratory for CH2M HILL to develop grout design mixes for possible use in producing fill materials as a part of Tank Closure of the Single-Shell Tanks at Hanford. The grout development data provided in this report demonstrates that these design mixes will produce fill materials that are ready for use in Hanford single shell tank closure.

Grout design mixes, based on Savannah River experience, were developed for the stabilization, structural and capping layers for use in filling tanks as part of Hanford Single Shell Tank Closure. These three design mixes, using Hanford area materials, meet the fresh requirements of flow ( $>12$ inches by ASTM D 6103), bleed water (no bleed water), and set time ( $<24$ hours). They also address the stabilization of the residual waste by encapsulation (or partial covering) of solid particles and by incorporation of supernate and associated constituents of concern within the grout itself.

These grouts also meet the cured property requirements of compressive strengths for the stabilization and structural grouts (>50 psi), the higher compressive strength requirement for the capping grout (>2,000 psi) to deter an inadvertent intruder, and prevention of subsidence.

Other properties of interest were also measured for these grout mixes. The effective diffusion coefficient, measured by an accelerated ANSI/ANS 16.1 procedure provides input to simulations that predict the release of Tc-99 from the grout. The values of the effective diffusion coefficients for formulations made from the binder materials and using distilled water as the leachant, range from $6.17 \mathrm{E}-10$ to $4.0 \mathrm{E}-12 \mathrm{~cm} / \mathrm{sec}$ with approximately $95 \%$ confidence.

Another property of concern is the shrinkage of the grout with time. The results of this test on the stabilization and structural grout mixes revealed very little shrinkage $(0.008 \%$ and $0.003 \%$ respectively).

The stiffness of the cured grout can be estimated by measuring Young's Modulus. The values for Young's Modulus ranged from 2.3E+05 to 3.6E+05 psi for the Hanford design mixes.

The saturated hydraulic conductivity of the grout mixes was also determined and can provide input for advection modeling. The values obtained for the three mixes range from 2.5E-07 to $5.9 \mathrm{E}-08 \mathrm{~cm} / \mathrm{sec}$.

The air content was measured for the Hanford stabilization grout (4.0\%) and the structural grout (6.5\%).

Qualitative measurements of the adiabatic temperature rise were also determined for the three Hanford mixes. These results were used to support calculations by ARES during design. The calculations were performed to predict the temperature rise within the tank as a function of placement rates. 
A dry powder mix of fly ash, blast furnace slag, and portland cement was developed and demonstrated during scale-up testing for placement in the single shell tank to solidify residual supernate as required.

A proof-of-principle demonstration was performed to show that cascade lines can self-seal during placement of grout in the single shell tank. Self-sealing under normal grout placement will preclude the necessity of sealing these lines by excavation and closure.

At the end of tank filling, it may be necessary, depending on the tank and riser configuration, to pump grout against a head of fresh grout. Placement against a head of 8 feet of fresh grout was successfully demonstrated during scale-up testing.

Placement through a Tremie and slick line were also successfully demonstrated for these grout mixes. 


\subsection{REFERENCES}

1. Langton, C. A. and Harbour, J. R., WSRC-RP-2003-01128, Rev. 1, Hanford Grout Specifications for High-Level Waste Tank Closure, May, 2004.

2. Lorier, T. H., Miller, D. H., Mhyre, W. L., Harbour, J. R., and Langton, C. A., WSRC-TR-200300447, Rev. 0, Grout Formulations for Closing Hanford High-Level Waste Tanks - Bench-Scale Study, September, 2003.

3. Langton, C. A., Harbour, J. R., Miller, D. H., Mhyre, W. L., Shramek, C. N., Carroll, J., Johnson, E., and Furgeson, A. L., WSRC-TR-2003-00556, Rev. 0, Grout Placement and Property Evaluation for Closing Hanford High-Level Waste Tanks - Scale-Up Testing, December, 2003.

4. Harbour, J. R., Edwards, T. B., Lorier, T. H., Langton, C. A., Moore, R. C., Krumhansl, J. L., Holt, K. C., Salas, F. and Sanchez, C. A., Stabilizing Grout Compatibility Study, WSRC-TR2004-00021, Rev. 0, January 2004.

5. Harbour, J. R., Langton, C. A. and Siler, J. L., WSRC-TR-2004-00626, Rev. 0, Report on Cascade Line Testing for Hanford Single Shell HLW Tank Closure, December, 2004.

6. Caldwell, T. B., D’Entremont, P. D., Langton, C. A., Newman, J. L., Saldivar, E. and Rajendran, N., Closing High-Level Waste Tanks at the Savannah River Site, R Radwaste Magazine, March 1998.

7. SRS Tank Closure, Innovative Technology Summary Report, DOE/EM-0449, August 1999.

8. Notice of Intent to Prepare an Environmental Impact Statement for Retrieval, Treatment, and Disposal of Tank Waste and Closure of Single-Shell Tanks at the Hanford Site, Richland, WA, 68 FR 03318, Federal Register, January 3, 2003.

9. Williams, J. C., Historical Vadose Zone Contamination from A, AX and C Tank Farm Operations, RPP-7494, Rev.0, 2001.

10. Khaleel, R. Connelly, M. P., Crumpler, D., Jones, T. E., Knepp, A. J., Mann, R. M., McMahon, B., Miller, C. W., and Wood, M. I., Modeling Data Package for an Initial Assessment of Closure for C Tank Farm, RPP-13310, Rev. 0, April 2003.

11. Single-Shell Tank System Closure Plan, RPP-13774, Rev. 2.

12. Dangerous Waste Regulations, Washington Administrative Code, WAC 173-303.

13. Radioactive Waste Management, DOE Order 435.1, 1997

14. Licensing Requirements for Land Disposal of Radioactive Waste, Code of Federal Regulations, 10 CFR 61.

15. Langton, C. A., Spence, R. D. and Barton, J., State of the Art Report on High-Level Waste Tank Closure (U), WSRC-TR-2001-00359, Rev. 0, July, 2001. 
16. Tank Closure Fill System for the Accelerated Tank Closure Demonstration Level 2 Specification, RPP-11904, Rev. 1, CH2M HILL Hanford Group Inc., Richland Washington, 2003.

17. Tank Closure Fill System for the Accelerated Tank Closure Demonstration Level 2 Specification, Draft RPP-17704, Rev. 0, CH2M HILL Hanford Group Inc., Richland Washington, August 2003.

18. Radiological Performance Assessment for the E-Area Low-Level Waste Facility. WSRC-RP-94218, Rev. 1.Westinghouse Savannah River Company, Aiken, SC. January 31, 2000.

19. Focused Feasibility Study of Engineered Barriers for Waste Management Units in 200 Areas, DOE/RL-93-33, Rev. 1, U.S. Department of Energy, Richland Operations Office, 1996

20. Schwochau, K., Technetium, Wiley-VCH, 1999.

21. Langton, C. A., Slag Based Materials for Toxic Metal and Radioactive Waste Stabilization, DPMS-87-95, Rev. 2, 1995.

22. Gilliam, T. M., Spence, R. D., Bostick, W. D., and Shoemaker, J. L., Solidification/Stabilization of Technetium in Cement Based Grouts, J. Haz. Mater., 24, 1990

23. Shuh, D. K., Final Report, Research Program to Study the Fundamental Chemistry of Technetium, EMSP-60296, 2000.

24. Kaplan, D. I. and Hang, T. Estimated Duration of the Subsurface Reducing Environment Produced by the Z-Area Saltstone Facility, WSRC-RP-2003, Rev. 2, January 2003.

25. Measurement of the Leachability of Solidified Low-Level Radioactive Wastes by a Short-Term Test Procedure, ANSI/ANS 16.1, 1986, prepared by the American Nuclear Society Standards Committee Working Grout ANS-16.1, Approved April 14, 1986 by the American National Standards Institute, Inc.

26. Pierce, E. M., McGrail, B. P., Rodriguez, E. A., Schaef, H. T., Saripalli, K. P., Serne, R. J., Krupk, K. M., Martin, P. F., Baum, S. R., Geiszler, K. N., Reed, L. R. and Shaw, W. J., Waste Form Release Data Package for the 2005 Integrated Disposal Facility Performance Assessment, PNNL-14805, 2004

27. Deutsch, W. J., Cantrell, K. J., Krupka, K. M., Brown, C. F., Lindberg, M. J. and Schaef, H. T., Hanford Tanks 241-C-203 and 241-C-204: Residual Waste contaminant Release Model And Supporting Data, PNNL- 14903, October 2004.

28. Deutsch, W. J., Cantrell, K. J., Krupka, K. M., Brown, C. F., Lindberg, M. J. and Schaef, H. T., Hanford Tanks 241-C-106: Residual Waste contaminant Release Model And Supporting Data, PNNL- 15187, June 2005.

29. Miller, B. and Chapman, N., Postcards from the Past: Archeological and Industrial Analogs for Deep Repository Materials, Radwaste Magazine, 2, 1995.

30. Mallinson, L. G. and Davies, I. L., An Historical Examination of Concrete in Nuclear Sciences and Technology, Rep. EUR10937EN, 1987.

31. Jull, S. P. and Lees T. P., Studies of Historic Concrete, Rep. EUR12972EN, 1990. 
32. Aloy, A. S., Suvorova, G. N and Holtzscheiter, E. W., Evaluation of Durability of Mortars and Concretes Used in Ancient Structures, WSRC-RP-2005-01551, Rev. 0, June, 2005

33. Industrial Wastewater Closure Plan for F- and H-Area High Level Waste Tank Systems, Rev. 1, July, 1996.

34. Industrial Wastewater Closure Module for the High Level Waste Tank 20 System, Rev. 1, January, 1997.

35. Industrial Wastewater Closure Module for the High Level Waste Tank 17 System, Rev. 1, August, 1997.

36. Harbour, J. R., Presentation to the Waste Management Committee CAB, Grout in HLW Tanks, WSRC-MS-2005-00018, Rev 0, January 2005.

37. Rajendran, J., Procurement Specification for Tank Closure - Furnishing and Delivery of Tank Fill Materials and Reducing Grout, C-SPP-F-00038 Rev 3, 2003.

\section{ASTM REFERENCES}

ASTM C 33-03, Standard Specification for Concrete Aggregates, American Society for Testing and Materials, Philadelphia PA.

ASTM C 128-01, Standard Test Method for Density, Relative Density (Specific Gravity), and Absorption of Fine Aggregate, American Society for Testing and Materials, Philadelphia PA.

ASTM C 136-01, “Standard Test Method for Sieve Analysis of Fine and Coarse Aggregates,” American Society for Testing and Materials, Philadelphia PA.

ASTM C 138-01, Standard Test Method for Density (Unit Weight), Yield, and Air Content (Gravimetric) of Concrete, American Society for Testing and Materials, Philadelphia PA.

ASTM C 150-89, Standard Specification for Portland cement, Annual Book of ASTM Standards Section 4 Construction, Vol. 04.02, Concrete and Aggregates, American Society for Testing and Materials, Philadelphia PA.

ASTM C 157, Length Change of Hardened Hydraulic-Cement Mortar and Concrete, American Society for Testing and Materials, Philadelphia, PA.

ASTM C 215-02, Standard Test Method for Fundamental Transverse, Longitudinal, and Torsional Resonant Frequencies of Concrete Specimens, American Society for Testing and Materials, Philadelphia PA.

ASTM C 231-97, Standard Test Method for Air Content of Freshly Mixed Concrete by the Pressure Method, American Society for Testing and Materials, Philadelphia PA.

ASTM C 232-99, Standard Test Methods for Bleeding of Concrete, American Society for Testing and Materials, Philadelphia PA. 
WSRC-TR-2005-00195

Revision 0

ASTM C 403-99, Test Method for Time of Setting of Concrete Mixtures by Penetration Resistance,” American Society for Testing and Materials, Philadelphia PA.

ASTM C 469-02, Standard Test Method for Static Modulus of Elasticity and Poisson's Ratio of Concrete in Compression, American Society for Testing and Materials, Philadelphia PA.

ASTM C 494-99, Standard Specification for Chemical Admixtures for Concrete, American Society for Testing and Materials, Philadelphia PA.

ASTM C 618-92, Standard Specification for Fly Ash and Raw or Calcined Natural Pozzolans for Use as a Mineral Admixture in Portland Cement Concrete, Annual Book of ASTM Standards Section 4 Construction, Vol. 04.02, Concrete and Aggregates, American Society for Testing and Materials, Philadelphia, PA.

ASTM C 989-89, Specification for Ground Granulated Blast-Furnace Slag for Use in Concrete and Mortars, Annual Book of ASTM Standards Section 4 Construction, Vol. 04.02, Concrete and Aggregates, American Society for Testing and Materials, Philadelphia PA.

ASTM D 6103-97, Standard Test Method for Flow Consistency of Controlled Low Strength Material (CLSM), American Society for Testing and Materials, Philadelphia, PA.

ASTM D-5233 1992 (R 1999) Standard Test Method for Single Batch Extraction Method for Waste Distribution, American Society for Testing and Materials, Philadelphia, PA 19103.

ASTM D-4646 1987 (R 2001) Standard Test Method for 24-Hour Sorption Test and Distribution Ratios by the Short-Term Batch Method, American Society for Testing and Materials, Philadelphia, PA 19103.

ASTM D-4319, 1993 (R 2001) Standard Test Method for Distribution Ratios by the Short-Term Batch Method, American Society for Testing and Materials, Philadelphia, PA 19103. 


\section{Distribution:}

E.W. Holtzscheiter, 773-A

D.A. Crowley, 773-A

S.L. Marra, 999-W

J.E. Marra, 773-A

A.D. Cozzi, $\quad$ 999-W

J.R. Harbour, 773-42A

C.A. Langton, 773-43A

T. B. Edwards 773-42A

S.M. O’Toole, $\quad$ CH2M HILL

R.B. Calmus, $\quad$ CH2M HILL

T.L. Sams, $\quad$ CH2M HILL

R.M. Mann, $\quad$ CH2M HILL

M.P. Connelly, $\quad$ CH2M HILL 